\title{
Monthly Industrial Output in China since 1983
}

\begin{abstract}
:
Monthly economic indicators are used for a variety of purposes, from studying business cycles to determining economic policy and making informed business decisions. China's published monthly industrial output statistics could hardly be more confusing, with changes in variables, in coverage, in measurement, and in presentation. This paper reviews the available official data and proceeds to construct a monthly industrial output series in nominal terms and in real terms for the period since May 1983, economy-wide and for the state sector.
\end{abstract}

JEL codes, all China:

C80 Data Collection and Data Estimation Methodology; Computer Programs - General

C43 Econometric and Statistical Methods: Special Topics - Index Numbers and Aggregation

E01 Measurement and Data on National Income and Product Accounts and Wealth; Environmental Accounts

E23 Macroeconomics - Production

O53 Economywide Country Studies - Asia including Middle East

O47 Economic Growth and Aggregate Productivity - Measurement of Economic Growth etc.

P24 Socialist Systems and Transitional Economies - National Income, Product, and Expenditure, Money, Inflation

Keywords: China industrial output, industrial growth, monthly industry data, public sector industrial output, Chinese statistics

Carsten A. Holz

Stanford University

Stanford Center for International Development

366 Galvez Street

Stanford, CA 94305-6015

E-mail: carstenholz@gmail.com,cholz@stanford.edu

10 January 2013 


\section{Table of Contents}

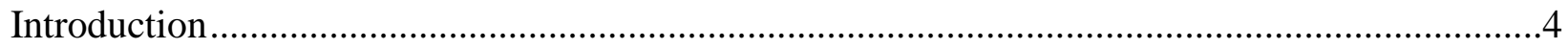

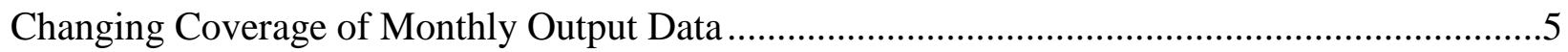

Incomplete and changing enterprise coverage …………...................................................6

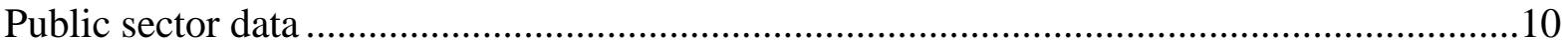

Data

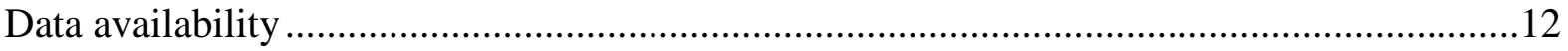

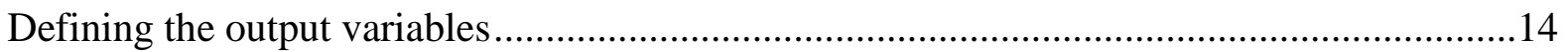

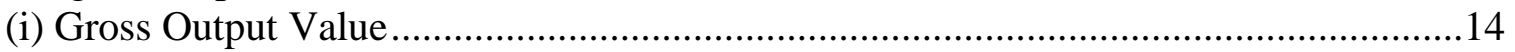

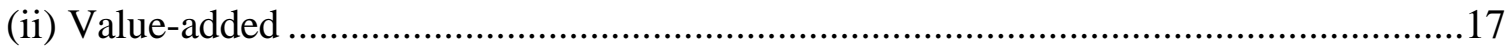

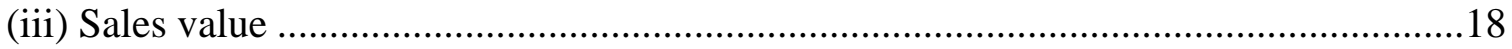

Constructing an Economy-wide Monthly Real Value-added Series ...........................................19

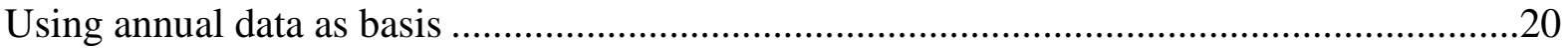

Splicing monthly real growth rate series of the directly reporting industrial enterprises ........21

Comparing the results of the two procedures ....................................................................22

Constructing an Economy-wide Monthly Nominal Value-added Series.........................................23

Constructing Public Sector Monthly Real and Nominal Value-added Series ................................25

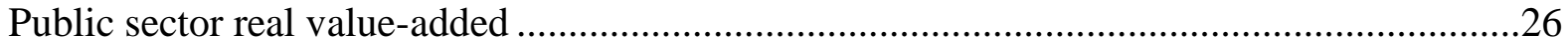

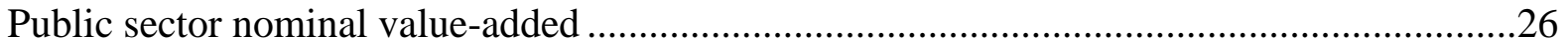

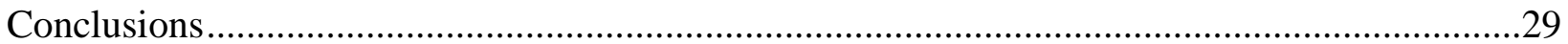

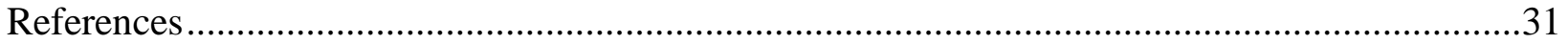




\section{Abbreviations}

b billion

c cumulative (monthly): January, January plus February, January plus February plus March, etc.

DRIE(s) directly reporting industrial enterprise(s)

GOV gross output value

m million

NBS National Bureau of Statistics

$\mathrm{SOE}(\mathrm{s}) \quad$ state-owned enterprise(s)

SOSCE(s) state-owned and state-controlled enterprise(s)

VA value-added

yoy year-on-year (such as November this year compared to November last year) 


\section{Monthly Industrial Output in China since 1983}

\section{Introduction}

Monthly data on China's industrial sector appear a hopeless jumble. Time series end for no apparent reason in one publication but not in another, then end in all publications while new series begin. A source may report gross output value data at constant prices for one month and cumulative value-added at current prices for the next month. Values rise or fall from one month to the next solely due to changes in enterprise coverage.

The National Bureau of Statistics (NBS) began to publish monthly industrial output data in May 1983. The available monthly industrial output data vary along a number of dimensions:

- variables: gross output value (GOV), value added (VA), "production sales" or "sales value;"

- coverage: all of industry or some subset of industry;

- values at current or at constant prices;

- monthly values or cumulative monthly values; and

- levels or growth rates.

No one consistently defined series runs from May 1983 through today.

The objective of this paper is to construct consistent monthly series of nominal and real (constant price) output for the years since 1983, economy-wide and for the public sector. These four constructed series can easily be subjected to a de-seasonalizing procedure. They can be turned into month-on-month growth rates (for example, November this year compared to October this year) or year-on-year (yoy) monthly growth rates (for example, November this year 
compared to November last year). Values for the non-state sector can be obtained as difference of the economy-wide values and the state sector values.

In order to derive the four series, different series of published data have to be spliced or transformed, and a number of decisions have to be made. For example, the first series in Figure 1 (diamond symbol) shows monthly real VA obtained from published monthly data, the second series (square symbol) annual real VA split into monthly real values using monthly data. The second series - based on annual economy-wide (industrial) real VA-in recent years grows much slower than the published series of monthly values (de facto, covering only the directly reporting industrial enterprises). The differences are significant. Thus, which data ones uses, matters. Pretending that the published monthly data that one uses (covering only the directly reporting industrial enterprises) reflect all industry would seem impermissible.

[Figure 1 about here]

The paper proceeds in three steps. The over time changing coverage of monthly output data is discussed first. This is followed by a description of the available data and of minor manipulations of some of the available data. The core sections of the paper describe how the desired four monthly time series are derived and report these final data, followed by a brief conclusion.

\section{Changing Coverage of Monthly Output Data}

Issues that beset all monthly industrial output data are the incomplete enterprise coverage and frequent changes in enterprise coverage. Similarly, the definition of the public sector evolved over time. 


\section{Incomplete and changing enterprise coverage}

The available monthly industrial output data cover only the directly reporting industrial enterprises (DRIEs). The definition of the DRIEs changed in 1998, 2004, 2005, 2007, and 2011. ${ }^{1}$ A key distinction is between the pre-1998 and post-1997 definitions:

- Through 1997: All industrial state-owned enterprises with independent accounting systems, plus all non-state industrial enterprises at township level and above with independent accounting systems.

- Since 1998: All industrial state-owned and state-controlled enterprises with (de facto) independent accounting systems, plus all non-state industrial enterprises with independent accounting systems and annual sales revenue in excess of 5m yuan RMB. ${ }^{2}$

Subsequently, the economic census of 2004 led to a 7.7 percent upward revision of DRIE GOV and a 26.0 percent upward revision of the number of DRIEs. DRIVE VA was not revised (with no reason given as to why not). Two minor redefinitions occurred in 2005 and in 2007, and a major one in 2011:

- In 2005, the term "sales revenue" changed to "revenue from principal business."

- In 2007, the separate inclusion of all state-owned enterprises disappeared and only the size criterion was retained.

- In 2011, the size criterion changed from $5 \mathrm{~m}$ yuan to $20 \mathrm{~m}$ yuan.

In terms of a consistent time series of DRIE values, the 1997-1998, 2004, and 2010-2011 statistical breaks are likely non-negligible. Any attempt to use the official monthly industrial

See Holz (2013a) for details on the changing definitions and for an evaluation based on annual data.

The short-form label of the DRIEs in Chinese statistics changed simultaneously from "above-norm" to "above designated size" industrial enterprises. 
output values will have to make allowance for these statistical breaks. However, while the statistical breaks affect the aggregate, they do not appear to affect the monthly patterns.

Thus, the monthly pattern of 1998 is very similar to that of 1997 (Figure 2), despite the fact that the revised 1998 definition of DRIEs reduces the number of enterprises covered (and thereby industrial output). ${ }^{3}$ With neither annual nor monthly values of 2004 VA retrospectively revised following the 2004 economic census benchmark revision-despite the fact that annual GOV and enterprise numbers were revised - the monthly data exhibit no statistical break in 2004 (Figure

3). The 2005 change in the coverage of the DRIEs is not detectable in the data, nor are the 2007 and 2011 statistical breaks (Figure 3, Figure 4; with nominal monthly VA data ending in November 2006, the 2007 and 2011 statistical breaks are pictured using nominal monthly GOV).

[Figure 2, Figure 3, and Figure 4 about here]

The statistical breaks in the DRIE series and the lack of plausible adjustments to create a consistent time series suggest not to directly use the monthly DRIE data. The fact that the DRIEs constitute only a subset of industry also advises against the direct use of these data.

The only economy-wide industrial output data available are annual data, in form of both nominal VA and (annual) real VA growth rates. Thus one can use the annual data as the basis, and break them down into monthly values by applying each year's monthly distribution of DRIE industrial output. I.e., economy-wide annual industrial VA is split into monthly values using the monthly output pattern of the DRIE subset of all industry, the largest subset for which monthly industrial output data are available.

Underlying this procedure are three assumptions:

\footnotetext{
3 The figure shows annual output of the DRIEs to fall slightly between 1997 and 1998. This could be due either to the change in coverage, with a drop from 468,506 enterprises in 1997 to 165,080 enterprises in 1998 (Statistical Yearbook 1998, p. 444; 1999, p. 432), or to changes in annual output. Economy-wide industrial VA in the national income and product accounts rose 3.1\% in nominal terms in 1998 (Statistical Yearbook 1999, p. 55) while DRIE VA fell $2.1 \%$ in nominal terms (Statistical Yearbook 1998, p. 444; 1999, p. 429), making it likely that the re-definition of the DRIEs led to a reduced industrial output coverage for the DRIEs.
} 
- The annual industrial output data — published as part of China's national income and product accounts—are accurate.

- The monthly distribution of industrial output of the DRIEs is accurate.

- The distribution of monthly industrial output of the DRIEs is representative of the distribution of monthly industrial output of all industrial enterprises (and non-enterprise units).

Of all data published by the NBS, the national income and product accounts data are probably the most reliable. If one uses the annual data published most recently (for all years), these data incorporate various benchmark revisions. The VA for industry reported in the national income and product accounts covers all industrial productive activities across the economy (by enterprises and non-enterprise units), and thus constitutes the most comprehensive measure of economy-wide industrial VA.

One possibility to examine the accuracy of the distribution of the monthly industrial output data of the DRIEs - the second assumption - is to contrast the monthly data with annual data. Ideally, the monthly data sum to the separately published annual DRIE total. If they don't, then either the monthly or the annual data are problematic. Fortunately, the two values tend to come close. For example, the cumulative monthly current-price VA of the DRIEs in 2005 (the last complete year for which these particular monthly data are available) was $6,968.19 \mathrm{~b}$ yuan. This compares to an annual value of 7,218.70b yuan (Statistical Yearbook 2010, p. 514). I.e., the summed monthly value falls 3.5 percent short of the annual value. For state-owned and statecontrolled enterprises, the comparison is between a cumulative monthly figure of $2,760.10 \mathrm{~b}$ yuan and an annual figure of 2,717.67b yuan (Statistical Yearbook 2010, p. 524), i.e., the shortfall in this case is an excess of 1.6 percent.

The summed monthly value can differ from the separately published annual value if the two sets of data cover different groups of DRIEs. Thus, it could be that the annual DRIE data only cover those enterprises which meet the DRIE criterion at year-end, while each month's data may 
cover those enterprises which meet the DRIE criterion at month-end. If the (small) discrepancies were due to data errors, then one may want to assume that the reported monthly data fall short of the true monthly data by the same proportion (percentage) every month. The DRIEs report directly to the NBS, so unless the DRIEs face incentives to mis-report (or to more severely misreport) in one particular month (or set of months), why should the NBS get the data wrong in one month but not in another, or more wrong in one month than in another? ${ }^{4}$

One aspect of the third assumption - the distribution of monthly output of the DRIEs is representative of the distribution of monthly industrial output of all industrial enterprises - that can be checked is the representativeness of the annual DRIE values. Figure 5 shows that the DRIEs capture a varying degree of all industry over time. Apart from the statistical breaks in the definition of the DRIEs, additional data problems occur in 1993 and in the most recent years for which annual DRIE nominal VA data are available before their publication ends in 2007: both the 1993 and 1994 values are historically out of line, for no apparent reason; and DRIE VA cannot exceed economy-wide VA (DRIEs are a sub-category of all industry) but the published data claim this to be the case in 2007. While there is no possibility to know how non-DRIE output is distributed across the different months of the year (in the absence of any such data), at least the DRIEs account for the majority of all industrial output in all years. ${ }^{5}$

[Figure 5 about here]

Monthly (DRIE) industrial output data come with two further complications. First, no monthly DRIE output data on a single output variable are available for the whole period since the beginning of the monthly series in 1983. Different series have to be spliced. At times, this

\footnotetext{
4 One could suspect that some enterprises face incentives to over-report output in order to achieve growth targets, but it is unclear if such over-reporting necessarily favors particular months. Enterprises could also face incentives to underreport in order to avoid higher tax payments.

5 The correlation coefficient of state-owned and state-controlled enterprise (SOSCE) and non-SOSCE (i.e., DRIE minus SOSCE) monthly nominal VA between 1997 and November 2006-the complete time span for which the SOSCE data are available - is 0.977 (and for DRIEs and non-SOSCEs 0.998). I.e., if the monthly distribution of the non-SOSCEs is close to that of the DRIEs, then one may feel somewhat confident that the same holds for the case of the non-DRIEs.
} 
requires approximations in order to create a consistent transition, or to bridge what appear to be data problems.

Second, for any one output variable, the coverage of the DRIEs changes due to the redefinitions noted above. But as a visual inspection of Figure 2 through Figure 4 reveals, the changes to the definition of the DRIEs appear to not cause any changes in the monthly output pattern. There is also no theoretical reason why changes to the definition of the DRIEs should be correlated with changes in monthly output patterns. ${ }^{6}$

\section{Public sector data}

The published monthly industrial output data frequently come with a breakdown by ownership, though the ownership categories do not necessarily always add up to the total. Early on, the ownership classification is limited to the three categories of state-owned enterprises, collectiveowned enterprises, and "others." Later, in some statistics, the ownership classification becomes more refined. What is consistently available are data on some aggregate of state-owned enterprises. This aggregate expanded in 1998 from 'state-owned enterprises' (SOEs) to 'stateowned and state-controlled enterprises' (SOSCEs).

The official statistics at different times incorporate three different definitions of SOEs:

- "Unreformed," or "traditional," or "pure” SOEs, i.e., SOEs operating in accordance with the 1988 SOE law;

- "SOEs" as generally understood for the years through 1997: (i) unreformed SOEs (as in the previous definition), plus (ii) SOE-SOE joint operation enterprises (an extremely small category), plus (iii) solely state-owned limited liability companies;

\footnotetext{
$6 \quad$ Changes to the set of DRIEs also occur every year (and every month) as enterprises enter and leave the set of DRIEs. (An enterprise may grow in size and enter the set of DRIEs once it reaches the size requirement to be included in the DRIEs, or an existing DRIE may exit.)
} 
- SOSCEs (with data available since 1998): SOEs (as in the previous definition) plus all (other) shareholding companies (i.e., limited liability companies and stock companies) in which the state has a controlling share.

For the years prior to 1998, only SOE values have been published. Since 1998 (and exceptionally, 1997), values may cover SOEs only (of the unreformed type), or SOSCEs only, or values may be reported for both classifications.

In creating a public sector time series, a consistent "SOE" or "SOSCE" series is needed. The intention is to capture the complete public sector. It is only with the passing of the Company Law in 1992, to take effect on 1 July 1994, that the institutional form of a 'company,' whether a limited liability company or a stock company, was created. But trial cases occurred earlier (and the stock markets in Shanghai and Shenzen started operation in December 1990 and early 1991). In the data manipulations below, SOEs that are not "pure" SOEs or SOE-SOE joint operation enterprises or 100 percent state-owned limited liability companies-i.e., state-controlled limited liability companies with less than a 100 percent state share, plus state-controlled stock companies - are allowed to first appear in 1993. This implies the use of SOE data through 1992, SOSCE data starting with their first availability (for most output variables) in 1998, and for 1993-1997 adjusted SOE figures to capture the missing non-SOE SOSCEs. Since the intention of the adjustments to 1993-1997 data is to create a time series that at all times captures the complete public sector, the label "SOSCE(s)" will be used throughout unless there is a need to distinguish.

\section{Data}

To recap, the objective of this paper is to construct four monthly series:

- a nominal economy-wide series of industrial output, 
- a nominal public sector series of industrial output,

- a real (constant price) economy-wide series of industrial output,

- and a real (constant price) public sector series of industrial output.

None of these monthly series is available. The underlying rationale for the discussion in this section is that economy-wide annual industry VA is to be broken down into monthly values based on available monthly output data (nominal or real) for the DRIEs. Annual data are available for economy-wide industrial VA in the national income and product accounts published in the Statistical Yearbook series, both in nominal form and as real growth rates, for the years since 1978. The national income and product accounts do not include data by ownership, i.e., no such annual series are available for SOSCEs and other approaches will need to be considered in constructing a monthly public sector output series.

\section{Data availability}

Monthly data are available in a number of sources. These are:

- A sequence of 3 statistics magazines published by the NBS (here abbreviated " 3 magazines"):

Zhongguo tongji yuebao: 7/85 - 1989 (this Chinese language magazine may have been published earlier and later, but if so, these issues are not available in any of the major China libraries)

China Statistics Monthly (a collaboration between the NBS and the University of Illinois at Chicago): published approximately 1988 - end-1991 (or slightly later)

China Monthly Statistics (published by the NBS): March 1993 (or slightly earlier) today. 
- Zhongguo tongji (“China Statistics"), with data for 11/1990 - today. This Chinese language monthly NBS journal contains (text) articles, with 1-2 pages of summary statistics for one earlier month.

- People's Bank of China Quarterly Statistical Bulletin (here abbreviated "PBC Quarterly Statistical Bulletin"), bilingual, published by China's central bank, the People's Bank of China. The first issue was published in the first quarter of 1996 with data going back typically to 1994 , bilingual. ${ }^{7}$

- The NBS website at www.stats.gov.cn (here abbreviated "NBS" as data source).

- The online database CEIC (http://www.ceicdata.com/China.html). ${ }^{8}$

Table 1 summarizes the data availability in these sources, with "m" (in this table only) denoting "monthly" values, "c" denoting "cumulative monthly" values, dates being in the format month/year, and the most recent data checked being that of December 2011. ${ }^{9}$ (Sources with data through 2011 are likely to continue publication of these data in later months.) Not all sources consistently label industrial output as DRIE industrial output; some of the sources occasionally come with a note explicitly to that effect.

Some of the data come with inconsistencies, such as a December cumulative nominal value that is not compatible with the November cumulative nominal value (while a monthly, non-

$7 \quad$ The PBC Quarterly Statistical Bulletin is the source with the longest-running nominal VA and VA real growth rate data for DRIEs and SOSCEs, even though these values are originally compiled by the NBS.

8 Two further sources, not considered here, are the magazine China Monthly Economic Indicators, published by the NBS since 2000, and the magazine China's Latest Economic Statistics, published by CERD Consultants Limited in Hong Kong since possibly 1988. Both appear less accessible than the sources used here, and neither appears to report any data beyond what is reported in the sources used here. The August 2001 issue of the first reports nominal value-added of the DRIEs (with an ownership breakdown). The December 2009 issue of the latter reports VA real growth rates for the DRIEs with a breakdown by ownership.

The information in the table is likely to be accurate but possibly incomplete. I have not inspected every single monthly issue of every relevant source, but used my judgment in browsing through the various issues. The print sources, not available in their totality in any library except perhaps the Universities Service Center at Chinese University of Hong Kong, would probably cover one floor-to-ceiling shelf if placed together. When the source contains data on SOSCEs and/or SOEs, it typically also does so on other ownership forms. Sources with data through 2011 are likely to continue publication of these data in later months. 
cumulative December value is not available). January values are frequently not reported, especially since 2007, or only combined January/February values are reported.

Browsing through the table, two facts stand out. First, splicing two monthly real series (for GOV and VA) would yield a monthly real series for the complete period May 1983 through December 2011 (and the latter series continues to be published), for the DRIEs and for the SOESOSCE combination. Second, it is much harder to piece together a lengthy nominal series, with the earliest values starting in 1990 only. In working with economy-wide annual data as a basis, while it will be straightforward to break real annual data down into a monthly real series, some of the real monthly data of the earlier years will have to be drawn upon to break nominal annual data down into a monthly nominal series.

[Table 1 about here]

\section{Defining the output variables}

\section{(i) Gross Output Value}

Much more is known about the published annual GOV data than about the monthly GOV series, which typically comes with no explanations. A number of redefinitions and retrospective revisions to economy-wide annual GOV values of the early and mid-1980s are fortunately avoided with the monthly data, which are limited to the DRIEs. Economy-wide annual GOV of the years from 1991 through 1994 was retrospectively revised in 1995 following the 1995 industrial census. No revised annual data for the DRIEs were published, whether that is because no revision to these data was necessary, or because the NBS chose not to publish revisions.

In 1995, the NBS re-defined GOV to incorporate four changes, the most important of which is the new exclusion of the VA tax from GOV. In 1995, the exclusion of the VA tax reduces GOV by more than ten percent (but even with the exclusion in 1995, GOV rises in 1995 
compared to 1994). ${ }^{10}$ As a result, pre-1995 GOV data are not comparable to 1995 GOV data calculated using the new method. Many publications do not make apparent the statistical break in 1995 (or 1996), and some series may not have adopted the new stipulations.

Annual GOV data are published for the economy in total, by ownership categories, and for the DRIEs (in the Statistical Yearbook and in the Industrial Yearbook). Starting 2000, the economy-wide total de facto covers only the DRIEs. The implicit economy-wide total obtained by adding the GOV across all ownership categories exceeds the published economy-wide total starting 1996 and continues to exceed the economy-wide total even after 1999, when publication of GOV data on "urban and rural individual-owned enterprises" (chengxiang geti), one subset of industry, ends. The most likely reason is a switch to reporting GOV on SOSCEs rather than SOEs, which, in the absence of any adjustment to other ownership categories (such as the category "others") suggests double-counting of those SOSCE activities which were previously only captured in a non-SOE category. In sum, no economy-wide annual values are available starting 2000, and two sets of economy-wide values are available for 1996-1999.

The availability of nominal monthly GOV data is limited, with data for a few years in the mid-1990s and then, carried only by CEIC, data since 2003 for the DRIEs and the SOEs (likely in their narrowest definition of unreformed SOEs), not the SOSCEs. ${ }^{11}$ Real GOV data are available for May 1983 through June 2000 in form of a constant price series (through 1990 in 1980 prices, then in 1990 prices), ${ }^{12}$ and real growth rates for the years since 2003.

The monthly nominal data appear equally affected by the redefinition of GOV in 1995 as the annual data, with DRIE as well as SOSCE nominal GOV growth throughout 1996 around zero

\footnotetext{
10 The other three changes concern the pricing of specific goods and services and are far less important in value. For details, see Holz and Lin (2001).

11 CEIC does not provide details on its data sources beyond a statement that the data are from the NBS. CEIC does not specify that the 'total' GOV that it reports is limited to the DRIEs. A double-check against the 2011 annual DRIE GOV value published in the Statistical Yearbook 2012, p. 503, suggests that the CEIC data cover only the DRIEs, with the CEIC's cumulative December 2011 value exactly equal to the annual DRIE value reported in the Statistical Yearbook, and its summed monthly value 0.8 percent larger.

12 The published monthly values do not always come with an explicit note that the values are in 1980 or in 1990 prices. The fact that the values are constant price values is deduced from dispersed comments in the sources, though some of them contradictory, and from cross-checking data in different sources; the same holds for the choice of base year (which, however, is also simply a matter of plausibility).
} 
(after years of double-digit growth). The monthly real series appear unaffected. Presumably, the retrospective revisions to the annual economy-wide nominal data of the early 1990s did not carry through to the monthly data; monthly data were published soon after the period they cover and could not be revised in already published print publications, while a revised new monthly series was never offered, in print or online. This suggests that the level of the monthly data as well as the growth rates could be inaccurate.

In order to obtain a consistent real GOV series from May 1983 through June 2000, the values of the 1980 s are re-based to 1990 prices. This requires establishing the 1990 GOV values in 1990 prices, ${ }^{13}$ and then applying the real growth rates inherent in the 1983-1990 data (in constant 1980 prices) to the $1990 \mathrm{GOV}$ values in 1990 prices. The non-cumulative GOV values in 1990 prices for 1991 onwards (available through June 2000) are the published ones.

The same procedure is used to obtain a SOSCE real GOV series. An additional complication here is that while SOE real GOV data are available from May 1983 through December 1998, SOSCE real GOV data are available for 1997 and 1998 only (with the two subcategories "SOEs" and "state-holding companies"). With the assumption that the group of SOSCEs is identical to the group of SOEs up through 1992 (as argued above), SOSCE values for 1993 through 1996 have to be approximated in order to obtain a consistent SOSCE series for all years (SOEs through 1992, SOSCEs since then). This is done in two separate steps.

13 GOV values for 1990 in constant 1990 prices are not available. Two series (published in China Statistics) for 1990 through September 1993 - (i) yoy real growth rates of the cumulative constant price GOV values of the twelve months of 1991 (which are relative to the respective months in 1990), and (ii) cumulative constant price GOV levels (in 1990 prices) for the same period (months of 1991) —allow backing out the 1990 cumulative GOV values in 1990 prices. From these, individual monthly 1990 GOV values in 1990 prices follow. This procedure is legitimate because the published cumulative real growth rates in China Statistics are taking the switch in base year into account. Double-checking by calculating the growth rates for the published cumulative GOV level values in 1991 vs. 1990 show these to be in the 70 percent range, i.e., by far too high (presumably due to comparing 1991 GOV in 1990 prices to 1990 GOV in 1980 prices); in 1992 and 1993, the only other years for which the source (China Statistics) publishes these data, the real growth rates implicit in the published cumulative real data match the published cumulative real growth rates. The published real growth rates for cumulative 1991 GOV level values also make sense in long-run comparison. (In other instances, sources made explicit that real growth rates are based on comparable aggregates.) The long-run constant price monthly GOV values (published in the 3 magazines and used here) match the monthly and cumulative monthly values published in China Statistics, the source of the 1991 real growth rates, up to a fraction of a percentage point. 
1996 SOSCE values are obtained by applying the 1997 SOSCE VA yoy monthly real growth rates to the 1997 SOSCE real GOV values. A double-check based on applying the same procedure to SOE values suggests that this is a permissible procedure. ${ }^{14}$ Proxied SOSCE monthly GOV values of 1993-1995 are obtained by comparing the ratio of the summed monthly (annual) SOE real GOV to the summed monthly (annual) DRIE GOV in 1990-1998 to the similarly defined ratio for SOSCEs (instead of SOEs) in 1996-1998, and then creating a plausible transition between the 1992 SOE ratio and the 1996 SOSCE ratio to back out annual SOSCE values for 1993-1995. ${ }^{15}$ Monthly SOSCE values are obtained by imposing the corresponding year's SOE monthly pattern. ${ }^{16}$

\section{(ii) Value-added}

Nominal monthly data are available for 1995 (with incomplete 1994 data) through November 2006. ${ }^{17}$ Publication of monthly VA data ends at the same time as does the publication of annual DRIE VA, presumably due to the illogical discrepancy between published DRIE VA and industrial VA in the national income and product accounts in 2007, with the former, a subset of industry, larger than the latter, the total of all industry (Figure 5).

YoY monthly real growth rates are available for 1995 (with incomplete 1994 data) through December 2011. Since 2006, no January real growth rates are published. What is available are monthly and cumulative real growth rates for February through December. January real growth

\footnotetext{
14 Applying the 1997 monthly SOE VA real growth rates to the SOE real GOV data of 1997 yields proxied 1996 monthly SOE real GOV values. These proxied SOE monthly real GOV values are close to the published ones, with the largest difference being 1.5 percent in August 1996. (The difference in proxied vs. published values, in percent of the published values, for January through December 1996, are: -0.4, 0.2, 0.4, -0.2, -1.2, 0.4, 0.6, 1.5, 1.0, 0.8, 0.9, 0.8.)

${ }_{15}$ The detailed considerations for each year's approximated SOSCE share are available upon request. The SOE and (/) SOSCE ratio values of 1992 through 1997 are: (1992:) 0.5945 / adopt SOE value, (1993:) 0.5244 / 0.54 (plausible value), $0.4406 / 0.51$ (plausible value), 0.4449 / 0.51 (plausible value), $0.4196 / 0.5039$ (obtained after approximation via VA real growth), 0.3976 / 0.4827 (actual).

Another option would be to impose the 1996 SOSCE monthly pattern on the 1993-1995 difference between derived annual SOSCE values and summed monthly SOE values; the resulting series is near-identical to the one relying on the current year's SOE monthly pattern.

17 The available cumulative December 2006 value in China Monthly Statistics implies a highly problematic (very much too small) December 2006 monthly figure.
} 
rates for 2006 and 2007 can be approximated using all available information (with details relegated to a footnote). ${ }^{18}$

The same type of data series are available for SOSCEs as for DRIEs. Missing January real growth rates since 2006 are addressed using the same procedure as in the case of the DRIEs.

\section{(iii) Sales value}

Monthly nominal sales values of the DRIEs and of various ownership forms within the DRIEs, including SOSCEs, are available in China Monthly Statistics starting 2007, except for January in each year, in monthly and in cumulative monthly form. ${ }^{19}$ The CEIC database reports "industrial sales" for the months since March 1992 (and for SOEs since March 1992, with no data on SOSCEs), including all January values.

The nominal sales values are very similar to the nominal GOV values, available for some years. Comparing the nominal sales values in CEIC to the nominal GOV values available for 10/93-6/98 in Zhongguo tongji or, equally, in CEIC, the average ratio of GOV to sales value is 1.05 , with a standard deviation of 0.03 , a maximum of 1.12 and a minimum of 0.91 . For the

18 If one assumes zero month-on-month inflation (not unreasonable for the years since 2006), January real growth rates can be backed out as follows:

January nominal VA * unknown real growth rate over next 12 months +

February nominal VA * real growth rate over next 12 months $=$

'January + February' nominal VA * cumulative 'January + February' real growth rate over next 12 months. As a double-check, for January 2004/2005 (a period for which the January real growth rate is published), the equation becomes 334.42 (b yuan) $* 20.9 \%+370.93 * 7.6 \%=13.9 \%$, compared to the published cumulative February 2005 real growth rate of $16.9 \%$. As the derived value and the published value are not the same, something else must be going on. Inflation can only have a negligible effect. (In the absence of month-on-month inflation figures: yoy CPI inflation in January 2005 was 1.9\% and in February 2005 3.9\%.) With no theoretical explanation for the discrepancy, does the procedure yield plausible results over several years? The answer is positive. For January 2003-2004, the comparison is between a derived value of $15.0 \%$ and a published value of $16.6 \%$, for January 2002-03 between $17.1 \%$ and $17.5 \%$. The equation is used here to obtain January 2006 and January 2007 real growth rates $(12.8 \%$ and $24.2 \%)$.

Starting December 2006, nominal VA data are no longer published. Starting with the real growth rate of January 2008, equal weight is given to January and February VA levels, i.e., the nominal VA of January and February are assumed equal. This leads to a real growth rate of $15.4 \%$ in January 2008 (same as in February 2008), 3.4\% in January 2009 (when the U.S. financial crisis hit), 28.6\% in January 2010, and 13.3\% in January 2011.

19 Growth rates are also reported, for both the monthly and the cumulative monthly data, with a note to the table stating that the growth rates are in current prices. Calculating the growth rates of the nominal data and comparing these growth rates to the reported growth rates, the match is close, but almost never perfect. January values can be backed out from monthly February and cumulative monthly February data, or once could use the CEIC data, which include January values. 
period 2007-2010 (now using CEIC values throughout), these four values are 1.02, 0.01, 1.03, and 1.00 .

In calculating monthly distributions (monthly shares in the annual total, where the annual total is obtained as summed monthly values), therefore, the use of sales values should yield similar results as the use of nominal GOV. Double-checking for 2007-10, the maximum and minimum monthly differences can reach extremes of 0.08 and -0.17 , and the annual standard deviation is between 0.04 and $0.06 .{ }^{20}$ I.e., the monthly patterns in the nominal DRIE GOV data and in the nominal DRIE sales value data are extremely similar.

\section{Constructing an Economy-wide Monthly Real Value-added Series}

The construction of a monthly real growth or constant price output series for the whole period presents a choice between splicing real growth rates of different series (GOV, VA) of a changing subset of industry (the DRIEs with their re-definitions), or relying on a consistent economy-wide annual real output series that is then broken down into a monthly series using the available monthly distributions of real GOV and real VA of the DRIEs (the largest subset of all industry on which monthly data are available). The second procedure is the preferred one and described first.

All final data series are reported in Appendix 1. Appendix 2 has the supporting monthly data, Appendix 3 the supporting annual data. [Appendix 2 and Appendix 3 are to be posted on a website, and not to be included in the print paper.]

20 For each of the four years 2007-2010, the average / standard deviation / maximum / minimum of the differences in the monthly shares in summed monthly values between GOV and sales value are $0.00 / 0.06 / 0.08 /-0.16,0.00$ / $0.04 / 0.06 /-0.08,0.00 / 0.06 / 0.07 /-0.17,0.00 / 0.04 / 0.06 /-0.10$. When the summary statistics are based on the absolute values of the differences, the statistics are 0.04 / 0.04 / 0.16 / 0.01, 0.03 / 0.02 / 0.08 / $0.00,0.04$ / 0.04 /

0.17 / 0.00, 0.03 / 0.03 / 0.10 / 0.00, 


\section{Using annual data as basis}

The NBS publishes annual economy-wide industrial nominal VA and the corresponding real growth rates (for example, in the Statistical Yearbook series). Choosing 2002 as base year (for reasons explained below), an annual constant price industrial VA series (in 2002 prices) can be established. These annual industrial real VA values are broken down into monthly values using monthly DRIE values.

Given the interest in monthly economy-wide real VA, DRIE monthly real VA—rather than real GOV - is the obvious first choice as source of the monthly distributions to apply to the economy-wide annual industrial real VA. DRIE monthly VA real growth rates are available starting May 1994. The early VA data could be of poor quality; the 1993 and 1994 annual values appear problematic (Figure 5). DRIE constant price GOV data are available from May 1983 through June 2000 (and GOV real growth rates for 2003-2011).

In the following, the DRIE constant price monthly GOV series is used through 1997, and the DRIE VA monthly real growth rates for the years since $1998 .{ }^{21}$ This avoids the earliest monthly VA data, and the switch between the two series occurs in the year in which the DRIEs are being re-defined. As explained below, 1998 is also a year in which the monthly distributions of the two series is near-identical.

For the derivation of the monthly distribution of real VA, the monthly VA real growth rates are turned into constant (year 2002) price values by assuming no inflation in 2002, i.e., by accepting the nominal monthly VA data of 2002 as real values. The monthly distribution that is applied to the annual constant price economy-wide industrial VA then is derived from the constant price monthly GOV series (in 1990 prices) through 1997 and from the real monthly VA

21 Because the monthly DRIE constant price GOV data for 1983 are incomplete, covering only May through December 1983, assume that the same percentage of the annual total (in form of summed monthly values) is produced in the first four months of 1983 as in 1984 (summed months January through April: 30.9\%); then split the remainder, May through December 1983, using the available monthly data and start the series in May 1983. 
series (in 2002 prices) starting in 1998, by using each month's output share in the (summed monthly) annual total. ${ }^{22}$

How important for the monthly distribution is the choice of year in which to switch from real GOV to real VA data? Figure 6 shows the monthly distributions of DRIE real GOV and real VA in the overlapping years 1995-1999, for which both data series are available. Through 1997, the GOV growth rate series tends to be smoother; since 1998, there is virtually no difference between the two. ${ }^{23}$ This suggests that 1998 (as chosen here, or 1999) is the optimal year to splice the monthly distributions of the two series.

The ideal base year exhibits no inflation between the different months of this year, i.e., no month-on-month inflation between January and December. The only published data, however, are yoy values. Zero yoy inflation in all months of this year does not imply that prices do not change from one month to the next in this year; that would require that prices did not change between the same two months of the previous year, either, which in turn would require that prices did not change between the same two months of two years earlier, etc. In the absence of month-on-month inflation data, the criterion used here for choosing the base year is that it is a low-inflation year with several preceding years of low inflation. Examining all years 1983-2011, the period 1997-2003 stands out with relatively low monthly yoy inflation rates. Within the period 1997-2003, 2002 appears the best choice (Figure 7).

[Figure 6 and Figure 7 about here]

\section{Splicing monthly real growth rate series of the directly reporting industrial enterprises}

An alternative to relying on an annual series broken down into monthly values using DRIE monthly output distributions is to directly splice different series of DRIE monthly yoy real

22 Monthly distributions could also be derived from a number of other series, or combination of series. Thus, one could switch from constant price GOV to VA real growth rates in other years, or one could use constant-price GOV and GOV real growth rates throughout, bridging only the lack of relevant GOV data in 1999-2002 with some other variable.

${ }_{23}$ Taking the absolute value of the monthly difference between the two monthly distributions, the biggest 12month (summed monthly, annual) difference is 4.4 percentage points (compared to the annual distribution total of 100 percentage points) in 1995 and 1996, with values of 3.9, 2.2, and 2.2 in 1997-1999. 
growth rates and to assume that these real growth rates are representative of all industry. As in the previous case, the procedure chosen here is to switch from the constant price GOV series to the VA real growth series in 1998.

At first sight, it would seem impermissible to splice the real growth rates of two very different output series (GOV and VA). However, up through the early 2000s, the NBS operated with product-specific fixed prices that were used to value gross output at constant prices, and VA was obtained in a second step by multiplying GOV with a constant factor. What is astonishing is not so much the fact that the GOV and VA real growth rates of the DRIEs in the overlapping years are similar, as the fact that there is any difference at all (Figure 8). ${ }^{24}$

[Figure 8 about here]

A severe shortcoming of the spliced real growth rate series is its limitation to a subset of all industry (the DRIEs), which furthermore changes in definition over time (though the NBS may calculate real growth rates for consistently defined sets of DRIEs in each year). The assumption that non-DRIEs grow at the same rate as DRIEs is likely a stronger limitation than the additional assumption made when using annual data as basis, that non-DRIEs exhibit the same monthly distribution as DRIEs. The spliced series, anchored to the economy-wide monthly real (equals nominal) 2002 VA, is included in Appendix 1.

\section{Comparing the results of the two procedures}

The results of the two procedures, shown graphically in Figure 1 and Figure 9, differ. The monthly real VA series with underlying annual values grows slower than the series based on

24 See Holz (2013b) for details on NBS practices for calculating annual real output. Orlik (2012, p. 25) specifically for the monthly data writes that "getting from the raw output data to an estimate of value added means subtracting the value of intermediate inputs from the value of final output. [...] Making that calculation is time consuming, so for the monthly data, the NBS dispenses with the niceties and multiplies total output for the month by the ratio of total output to value added for the previous year." According to Orlik, real growth is obtained by applying the producer price index to nominal growth rates. Orlik's information is for the recent years. At least through the early 2000s, it is most unlikely that a producer price index was used (which did not become available with a sectoral breakdown until the early 2000s); the official data explanations point towards the use of product-specific constant prices (as is also indicated by the fact that the NBS published constant price GOV through June 2000). 
official DRIE monthly (GOV and VA) real growth rates. ${ }^{25}$ If the annual real growth rates are accurate, and if non-DRIEs grow at the same rate (or slower) than the DRIEs, then the yoy monthly real growth rates published by the NBS for the DRIEs are an exaggeration. On the other hand, if the DRIE yoy monthly real growth rates were accurate and were to furthermore accurately reflect real growth of all of industry, then industrial VA reported in the national and product accounts underestimates actual output; consequently, China's GDP real growth rates would also be underestimates. ${ }^{26}$

[Figure 9 about here]

Overall, the procedure based on annual data would seem superior. The quality of the monthly data is unlikely to be better than the quality of the annual data, and DRIE growth rates are unlikely to always be fully representative of all industry. Even if the monthly distributions of the DRIEs were to not to apply fully to the non-DRIEs, using annual data as a basis at least guarantees long-run economy-wide industrial yoy growth rates that are consistent with the national income and product accounts. ${ }^{27}$

\section{Constructing an Economy-wide Monthly Nominal Value-added Series}

Data on monthly nominal VA are scarce (Table 1). Reliance on annual values again constitutes a plausible solution.

To be consistent, the annual nominal values are ideally broken down into monthly values using the monthly nominal output distributions of the DRIEs. However, the availability of monthly nominal values is limited:

25 For the purpose of comparison, the DRIE monthly GOV/VA real growth series in Figure 1 is anchored to the 2002 monthly real VA of the economy-wide series based on annual data.

26 Maddison $(1998,2006)$ and Wu $(1993,2002)$ claim that China's official (annual) industrial real growth rates are exaggerated. (Their evidence is questioned by Holz, 2006a,b). Monthly real growth rates that are higher than the official annual real growth rates would, if accurate, and if they reflected the growth of all industry, point to exactly the opposite bias in the official data than the one claimed by Maddison and $\mathrm{Wu}$.

27 If the DRIE monthly distribution were to exhibit a consistent bias in comparison to the unknown economy-wide monthly distribution, yoy real growth rates could possibly not be affected at all. 
- VA: 1995 through 2006 (with an approximated December 2006 value); ${ }^{28}$

- GOV: March 1992 through 1998, 2003 through 2011;

- Sales value: March 1992 through 2011.

To obtain the monthly distributions for all years, the starting point is the nominal monthly VA data available for 1995 through 2000. For the years prior to 1995, one could use all available nominal GOV data (March 1992 or 1993 through 1994) combined with real GOV in all other years (1983 through February 1992 or end-1992); constant price GOV is the only series that is available for the months prior to March 1992. Table 2 suggests that the monthly distribution of the nominal and real GOV series are reasonably close, and in 1995 and 1996, the first two years for which the comparison is possible, equally match the distributions of the nominal VA data. To keep things simple, only constant price GOV is used for all years prior to 1995 to establish the monthly distributions. ${ }^{29}$

[Table 2 about here]

For the years after 2006, three choices of data are available: real VA, nominal GOV, or (nominal) sales value. Examining the last four years for which nominal VA is available (20032006), the DRIE monthly distributions of all three series match the monthly distribution of nominal VA very well; sales values fare best, with, on average, a month's share in annual sales value about 0.1 percentage points off that month's share in annual nominal VA (an average annual value of 1.2 in Table 2). Nominal GOV fares little worse (with an average annual value of 1.6) and is the theoretically better matching variable: VA equals GOV less intermediate inputs; VA and GOV are production-based concepts, unlike sales value which is a revenue-based

28 The December 2006 value is assumed to be 10 percent of the annual total. The decision was informed by the actual December share of 9.6 percent in 2005 and 10.2 and 10.6 percent in 2004 and 2003. For nominal GOV, the December shares in 2005-2007 are 10.3, 10.2, and 10.1 percent, and for sales values 10.5, 10.3, and 10.3 percent.

29 One could also switch from the real GOV to the nominal VA series in 1998, to coincide with the change in the definition of the DRIEs. Since the nominal VA data are directly available and do not require any manipulation, these data are used from the point in time when they become available (1995). Table 2 shows that the monthly distributions of real GOV and nominal VA are very similar in 1995-1997. 
concept (with sales values approximately equal to GOV less net additions to inventories). In the following, the monthly distributions inherent in the nominal GOV data of 2007-2011 are applied to the annual nominal VA data. ${ }^{30}$

\section{Constructing Public Sector Monthly Real and Nominal Value-added Series}

The national income and product accounts do not provide data by ownership. I.e., in the case of the public sector, foundation values in form of consistently defined series of annual nominal and real values are not available. Outside the national income and product accounts, some SOSCE annual output values are available. Those that are available are typically in nominal form. ${ }^{31}$

A plus in the case of SOSCE data is that the available monthly SOSCE data reflect virtually all SOSCEs. ${ }^{32}$ Thus, these monthly values are potentially of immediate relevance. This is unlike in the economy-wide case where no economy-wide monthly data were available and annual economy-wide data were broken down into monthly values using the monthly distribution of the largest subset of industry for which monthly data are available, the DRIEs.

\footnotetext{
30 In practical terms, if only sales value data are available, these will do just as well. The monthly distributions of nominal GOV and sales value are near-identical in 2008-2011, with the average month's share in annual GOV only 0.03 percentage points different from that month's share in annual sales value (Table 2). Compared to a month's $8.3 \%$ average share in the annual total $(100 \% / 12=8.3 \%)$, a difference of 0.03 percentage points is negligible.

31 The only SOSCE real annual values are GOV real growth rates for 1978 through 2003 (published in the Industrial Yearbook).

32 The 2004 economic census (Economic Census 2004, first secondary sector volume, pp. 2, 7, 10 and 101) reveals that not all state-owned enterprises are included in the DRIEs, even before the re-definition of the DRIE category to no longer specifically include all SOSCEs. All unreformed SOEs (as listed in the table on all industrial enterprises) vs. the unreformed SOEs included in the DRIE category numbered 25,339 vs. 23,417, with GOV of 2.35 vs. 2.34 trillion yuan, and with employment of 8.92 vs. $8.84 \mathrm{~m}$ laborers. For the state joint operation enterprises, the comparison numbers are 6547 vs. 1439 enterprises, 103 vs. $93 \mathrm{~b}$ yuan GOV, and 98,500 vs. 81,500 laborers. For the solely state-owned limited liability companies, the comparison numbers are 2083 vs. 1449 enterprises, 996 vs. 995 b yuan GOV, and 3.70 vs. $3.67 \mathrm{~m}$ laborers. Details on limited liability companies with controlling but less than $100 \%$ state ownership and on state-owned stock companies are not available; presumably, these are all large enough to be included in the DRIEs. In terms of GOV, the aggregate difference based on the available data (three categories with data above) is approximately 0.6 percentage points, and this difference would presumably be smaller if data on the missing two categories were available and included. No attempt is made in the following to bridge this slight difference between all SOSCEs and the SOSCEs included in the DRIEs (with data available only on the latter).
} 


\section{Public sector real value-added}

Because the monthly SOSCE data cover (nearly) all SOSCEs - and in the absence of consistently defined annual real values - the obvious procedure is to use the available monthly SOSCE constant price and real growth values. Constant price public sector monthly GOV values in 1990 prices are available for May 1983 through 1998 (with the necessary manipulations to derive a consistent SOSCE series explained above in the section on GOV). SOSCE monthly VA real growth rates are available since 1997.

A constant price monthly VA series in 2002 prices is obtained by assuming the 2002 SOSCE monthly nominal VA figures to also represent real values, and then to apply the available real growth rates to these constant price 2002 monthly values. The available SOSCE monthly VA real growth rates are used for the years since 1998, and the constant price GOV growth rates for the years prior to $1998 .^{33}$

\section{Public sector nominal value-added}

No monthly nominal output data are available for any year prior to 1993. This implies the need to either take recourse to (limited) annual data for at least the years prior to 1993 (and to apply some monthly distribution to these annual data) or to obtain SOSCE values as a share of the economy-wide values (either by using annual SOSCE shares and then applying a monthly distribution, or by using monthly SOSCE shares).

The following annual nominal SOSCE data are available at the time of writing:

- VA: 1992-2007 (Statistical Yearbook);

- GOV: 1978-2010 and ongoing (Industrial Yearbook);

- Sales value: 2001-2010 and ongoing (Industrial Yearbook).

33 Due to the manner in which constant price SOSCE monthly GOV values of 1996 were derived, the monthly constant price GOV growth rates and the monthly VA real growth rates in 1997 are identical. (See the section on GOV above.) 
Values on the same variables in the same years are also available for the DRIEs (GOV only starting 1986). Economy-wide VA data are further available for all years in the national income and product accounts, and economy-wide GOV values are available for 1978 through 1999.

The annual data (and by implication the corresponding monthly data) come with a number of questions. As noted above, DRIE nominal VA exceeded economy-wide total industrial VA in the national income and product accounts in 2007-logically not possible - before the DRIE (and, equally, the SOSCE) nominal VA series was discontinued. The SOSCE category is a subset of the DRIEs; if the DRIE VA data are of dubious quality, then the SOSCE VA data may be of dubious quality, too: it could be the case that only the VA of the non-DRIEs is problematic, and it could also be the case that the calculation of VA in this particular set of statistics is problematic across all ownership forms.

Monthly nominal SOSCE data are available for:

- VA: 1997 through November 2006;

- GOV: 1994 through 1998 (and, SOEs only, 2003-2011);

- Sales value: 2007 through 2011 (and, SOEs only, 1993-2011).

If SOSCE data were published together with economy-wide data, so that both sets of data are potentially equally problematic, the SOSCE share could still be accurate. But what is available are only (potentially problematic) SOSCE monthly values and problematic DRIE monthly values (not economy-wide values), or (potentially problematic) SOSCE annual values and (presumably accurate) economy-wide data. The issue cannot be resolved.

A key assumption in the following therefore is that the SOSCE data are accurate, even when the DRIE data are not. A rationalization would be that SOSCEs tend to maintain a reliable accounting framework, while the data of smaller, non-state enterprises (also included in the DRIEs) are likely of poorer quality. 
The procedure chosen here is to break the period May 1983 through 2011 into four subcategories.

- 1997-2005: directly use 1997-2005 published SOSCE monthly nominal VA data. ${ }^{34}$

- 2006-2011: calculate the share of monthly SOSCE real VA in 2002 prices in monthly economy-wide real VA in 2002 prices (both series derived above) and multiply this share by economy-wide nominal monthly VA (derived above).

- 1983-1992, 1996: multiply economy-wide nominal monthly VA (derived above) by a monthly SOSCE share obtained as a ratio (a)/(b): (a) use the monthly distribution of DRIE constant price GOV to break down economy-wide annual nominal GOV into monthly values; (b) use the monthly distribution of SOSCE constant price GOV to break down annual nominal SOSCE GOV into monthly values. ${ }^{35}$

- 1993-1995: these are the years for which only SOE values are available but SOSCE values should be used. Therefore, divide the earlier derived SOSCE monthly constant price GOV of 1993-1995 by the corresponding published SOE monthly constant price GOV to obtain a multiplication factor that turns SE into SOSCE values. To obtain the SOSCE share in nominal economy-wide VA for 1993-1995, use the same procedure as for the period '1983-1992, 1996'-where the values through 1992 are SOE values and non-SOE SOSCEs did not yet exist, and the 1996 values are SOSCE values - to calculate the monthly SOE shares of 1993-1995, and then multiply by the multiplication factor to turn SOE into SOSCE shares.

The transition between the 1997-2005 series and the 2006- series is unproblematic because the SOSCE share values in the economy-wide total in 2005 are very similar for real and nominal

34 These data end in November 2006; the series could run through 2006 if December 2006 values were approximated.

35 The GOV series are the original constant price series in 1980 and 1990 prices (i.e., have not yet been combined into one series at 1990 prices). 
values (Figure 10). I.e., either both SOSCE series, the real and the nominal series, are biased equally, or neither one is biased. The option of using the real series all the way starting in 1997 exists (rather than using the nominal series for 1997-2005), but since the intention is to have a nominal series, and since the two share series are so similar in 2005, it would seems preferable to use the available monthly nominal SOSCE VA data.

For the years prior to 1997, one has no choice but take recourse to the annual nominal GOV data and the monthly constant price GOV data. The trick is to use the available annual economywide and SOSCE nominal GOV data, obtaining monthly SOSCE shares by applying the DRIE monthly constant price distribution to the economy-wide annual values and the SOSCE monthly constant price distribution to the SOSCE annual value. The published annual GOV data on the public sector through 1995 cover only the SOEs, and the 1993-1995 values are consequently adjusted using the same procedure as above in the case of real growth rates. As Figure 11 shows, these measures create a plausible overall SOSCE share series with a transition from SOEs to SOSCEs in 1993 and from GOV-based calculations to nominal VA in 1997 (first series in Figure 11 through 1992 and in 1996, third series in 1993-1995 or 1993-1996, with equal 1996 values as the first series, and the second series for the years starting 1997).

[Figure 10 and Figure 11 about here]

\section{Conclusions}

In the absence of long-run monthly industrial output series for China, this paper constructed economy-wide and public sector monthly nominal and constant price series for the period May 1983 through 2011, with the possibility to extend these series forward using regularly published

official data. In contrast to the published monthly data, the series created here cover all industry (rather than just the DRIEs) and a consistently defined public sector (rather than operating with SOE vs. SOSCE series). The variable is value-added, as the most widely used measure of output. 
The monthly economy-wide series can easily be further manipulated as well as extended into the future. Thus, the series can be subjected to a de-seasonalizing procedure or turned into month-on-month or yoy growth rates, and values for the non-public sector can be backed out. Looking forward, they can be extended into the future by using the annual nominal VA and VA real growth rates published as part of the national income and product accounts (published, for example, in the Statistical Yearbook series, or, with a time lag, on the NBS website) and applying the DRIE monthly output distribution to these annual values. In the case of nominal VA, the appropriate monthly DRIE data are the nominal GOV data (available in CEIC) or, alternatively, the sales value data (available in the 3 magazines or CEIC); in the case of real VA, the appropriate DRIE data are the monthly yoy VA real growth rates (published, for example, in the PBC Quarterly Statistical Bulletin, in the 3 magazines, on the NBS website, and in CEIC, all requiring an approximation of January data using the yoy monthly and cumulative monthly February real growth rates and assuming identical January and February nominal output values), applied to the constant price VA series (in 2002 prices) provided here.

Constant price public sector monthly VA can be extended into the future by applying the SOSCE VA real growth rates (published, for example, in the PBC Quarterly Statistical Bulletin, in the 3 magazines, on the NBS website, and in CEIC, all requiring an approximation of January data) to the constant price public sector VA series (in 2002) prices provided here. Nominal public sector monthly VA can be extended into the future by applying a SOSCE share to the derived monthly economy-wide nominal values; where the SOSCE share is the ratio of (derived) SOSCE real VA in 2002 prices to (derived) economy-wide real VA in 2002 prices. 


\section{References}

CEIC. CEIC China Premium Database. http://www.ceicdata.com/China.html (by subscription only).

Economic Census 2004. Zhongguo jingji pucha nianjian-2004 (China Economic Census Yearbook-2004). Four volumes. Beijing: Zhongguo tongji chubanshe, (May) 2006.

Holz, Carsten A., and Yi-min Lin. "Pitfalls of China's Industrial Statistics: Inconsistencies and Specification Problems." The China Review 1, no. 1 (Fall 2001): 29-71.

Holz, Carsten A. "China's Reform Period Economic Growth: How Reliable Are Angus Maddison's Estimates? Review of Income and Wealth 52, no. 1 (March 2006a): 85-119.

Holz, Carsten A. "China's Reform Period Economic Growth: How Reliable Are Angus Maddison's Estimates? Response to Angus Maddison's Reply." Review of Income and Wealth 52, no. 3 (Sept. 2006b): 471-5.

Holz, Carsten A. "Chinese Statistics: Classification Systems and Data Sources .” Mimeo, Stanford Center for International Development, Stanford University, January 2013 a.

Holz, Carsten A. "Measuring Productivity Change in China, 1952-2010." Mimeo, Stanford Center for International Development, Stanford University, 2013b.

Industrial Yearbook. Zhongguo gongye jingji tongji nianjian (China Industrial Economy Statistical Yearbook). Beijing: Zhongguo tongji chubanshe, various years.

Maddison, Angus. Chinese Economic Performance in the Long Run. Paris: Development Centre of the Organisation for Economic Co-operation and Development, 1998.

Maddison, Angus. "Do Official Statistics Exaggerate China's GDP Growth? A Reply to Carsten Holz." Review of Income and Wealth 52, no. 1 (March 2006): 121-6.

Orlik, Tom. Understanding China's Economic Indicators: Translating the Data into Investment Opportunities. Upper Sddle River, New Jersey: FT Press Science, 2012.

Seventeen Years. Gaige kaifang shiqi nian de zhongguo diqu jingji (China's Regional Economy in Seventeen Years of Reform and Opening). Beijing: Zhongguo tongji chubanshe, 1996.

Statistical Yearbook. Zhongguo tongji nianjian (China Statistical Yearbook). Beijing: Zhongguo tongji chubanshe, various years.

Wu, Harry X. "The Real Chinese Gross Domestic Product (GDP) for the Pre-Reform Period 1952-77." Review of Income and Wealth 39, no. 1 (March 1993): 63-87.

Wu, Harry X. "How Fast Has Chinese Industry Grown?-Measuring the Real Output of Chinese Industry, 1949-97." Review of Income and Wealth 48, no. 2 (June 2002): 179-204. 


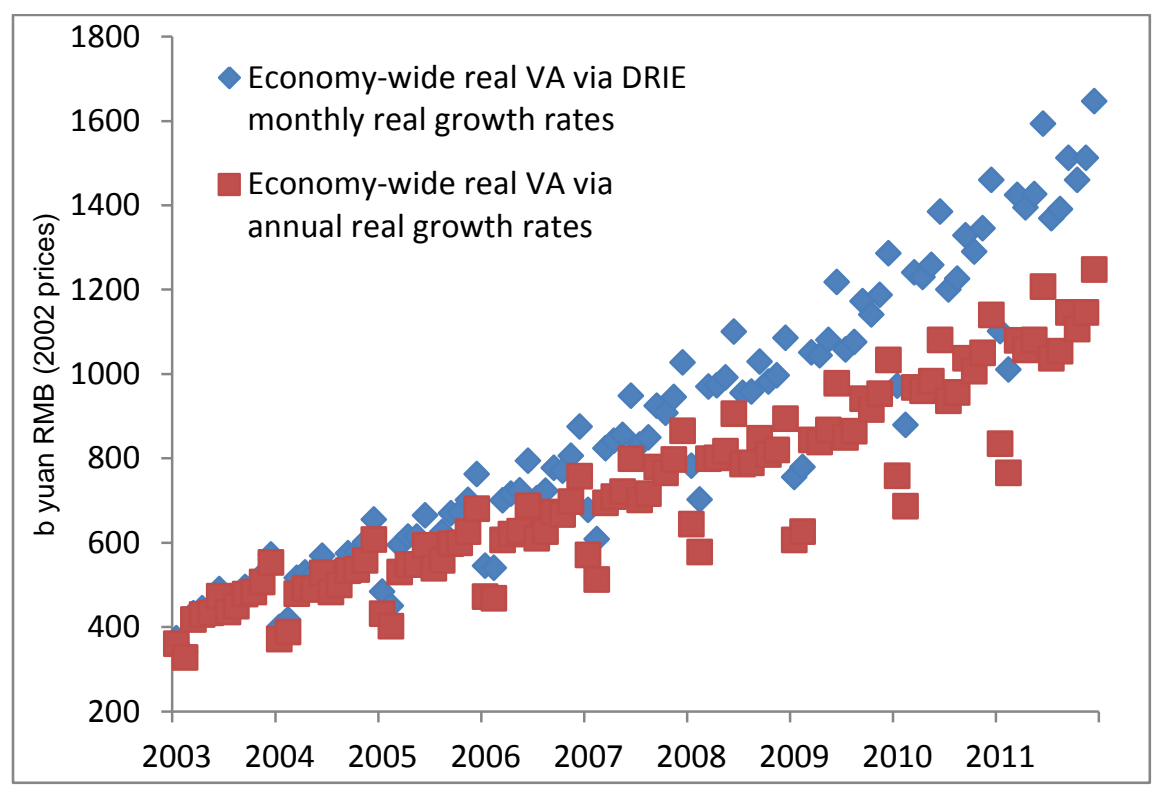

The first series, based solely on monthly values, combines DRIE real GOV growth rates through 1998 with DRIE real VA growth rates since then, and anchors them to the 2002 nominal VA values of the second series. The second series is based on nominal annual 2002 VA and annual real VA growth rates, with annual values broken down into monthly values using the DRIE monthly distribution.

Figure 1. Monthly (YoY) VA Real Growth Rates

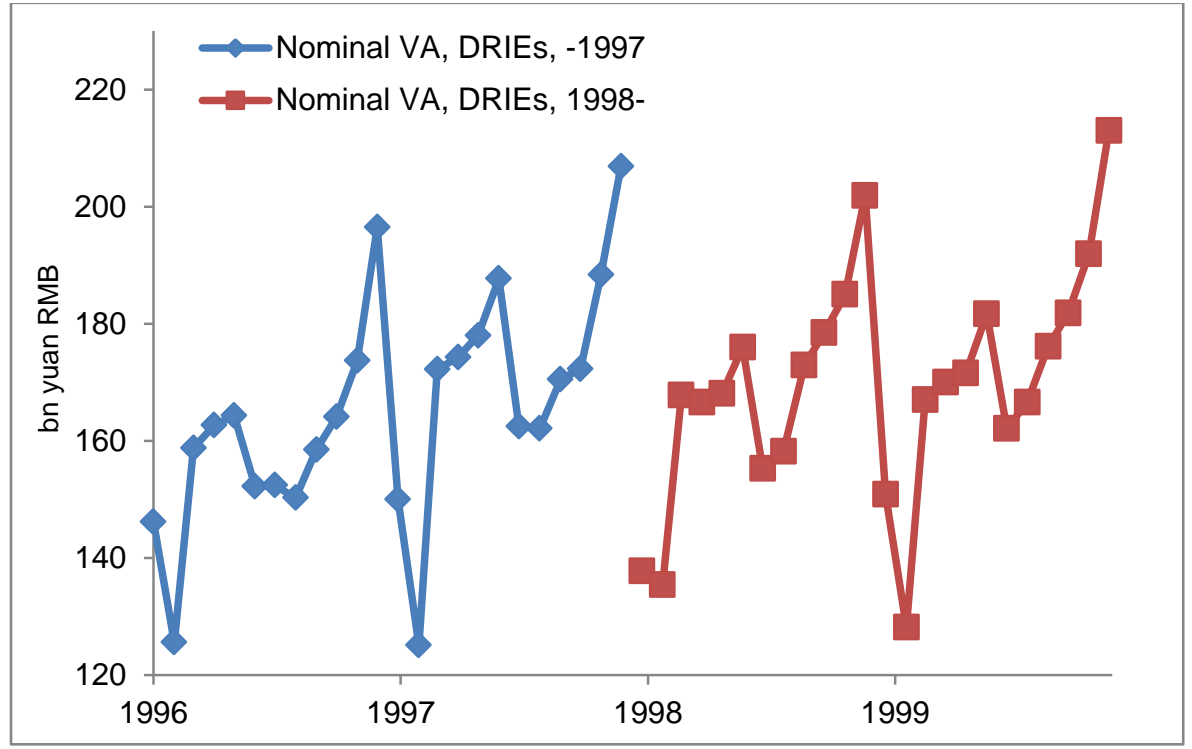

Figure 2. The 1998 Statistical Break in the DRIE VA Series 


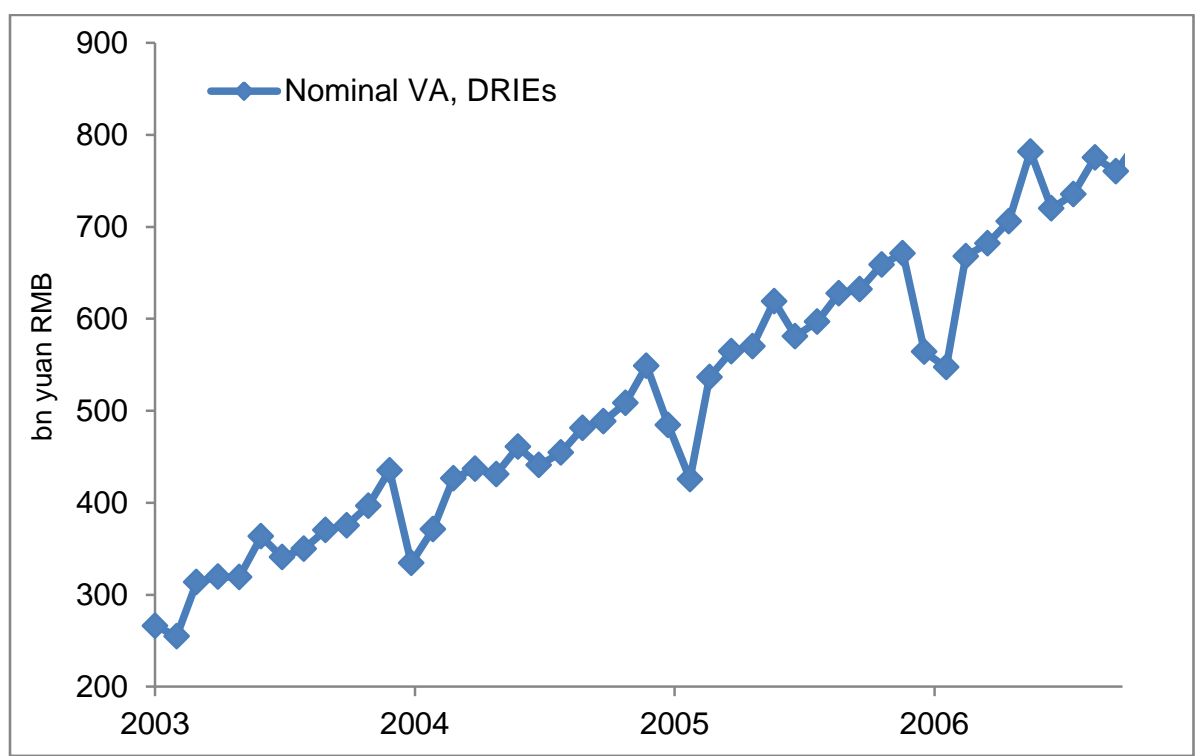

Figure 3. The 2004 and 2005 Statistical Breaks in the DRIE VA Series

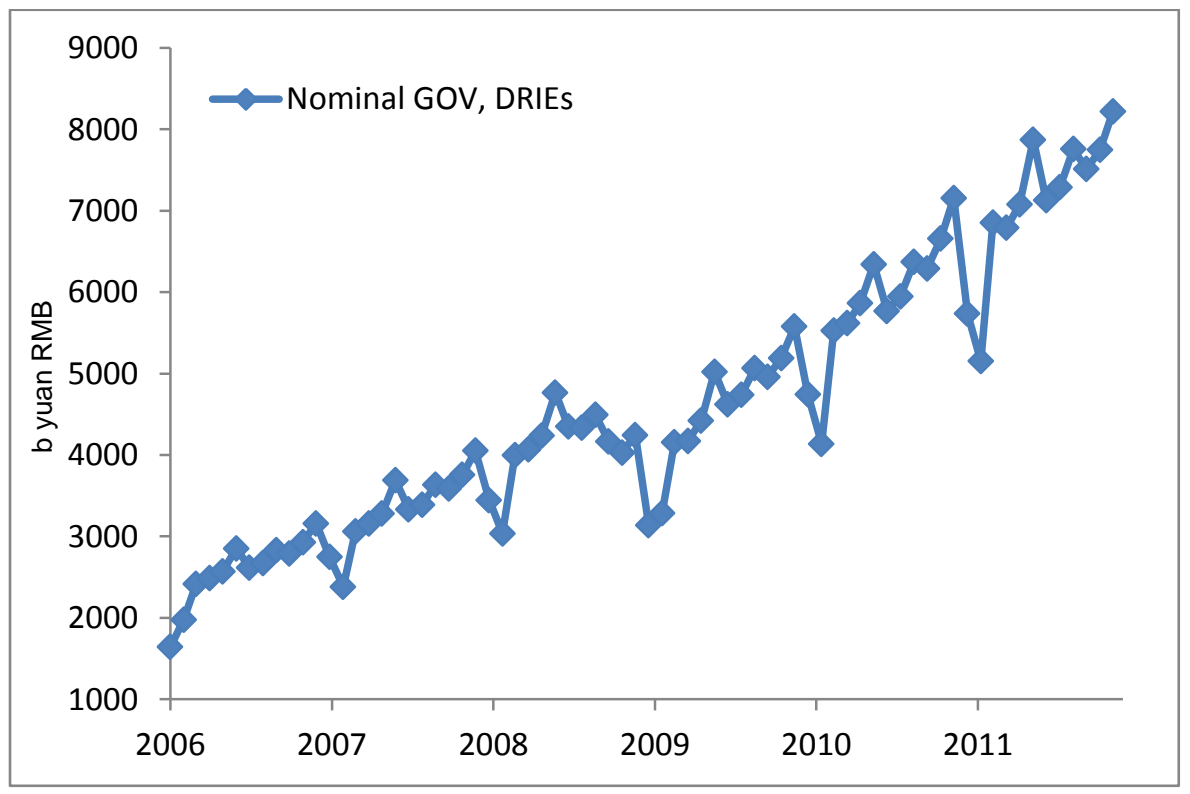

Figure 4 The 2007 and 2011 Statistical Breaks in the DRIE GOV Series 


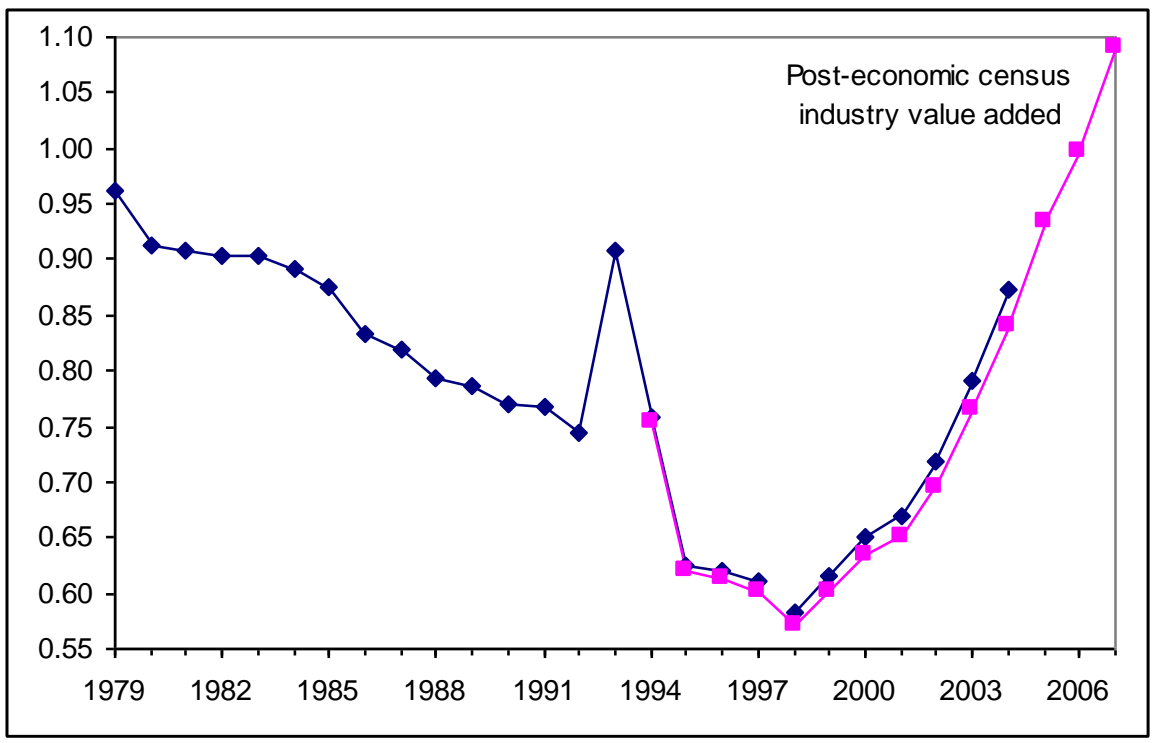

The second series (square markers) uses the post-economic census 2004 retrospectively revised economy-wide industrial VA data; DRIE VA values have never been revised.

DRIE VA of the years prior to 1992 are estimated by applying the ratio of 'industry VA to industry net material product' to the net material product values of the DRIEs (not available for 1979 and 1981). 1979 and 1981 DRIE VA are interpolated based on the ratio of DRIE GOV to constructed DRIE VA in 1980 and 1982 and the available DRIE GOV values of 1979 and 1981.

Sources: Statistical Yearbook and Industrial Yearbook, numerous issues; Seventeen Years.

Figure 5. DRIE Share in VA of Industry

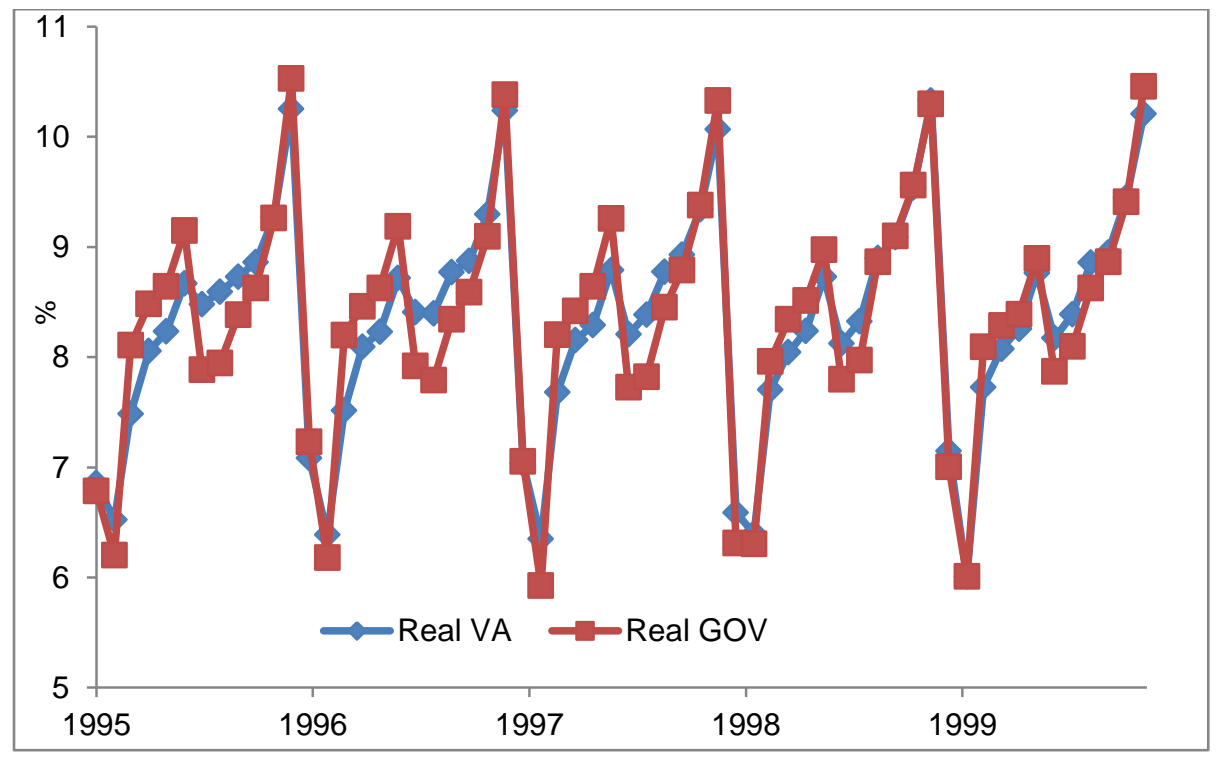

Figure 6. Monthly Shares in Annual DRIE Output 


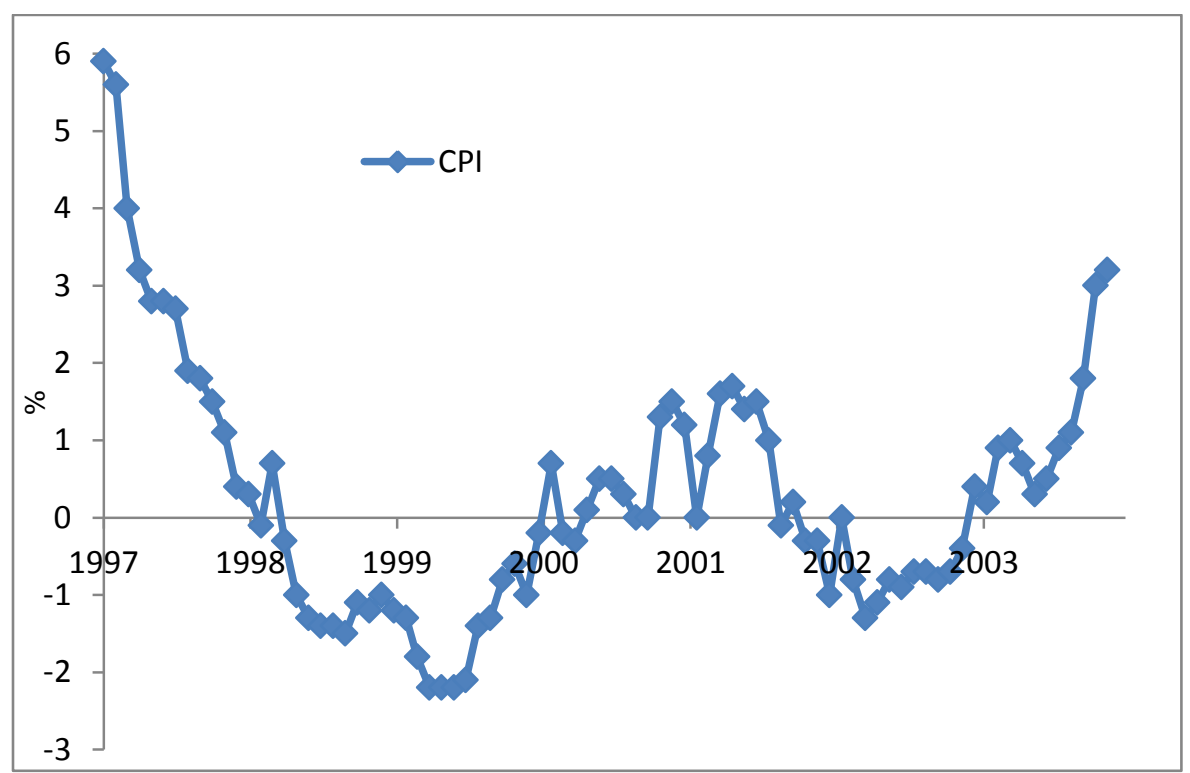

Source: 3 magazines.

Figure 7. YoY Monthly CPI (in percent)

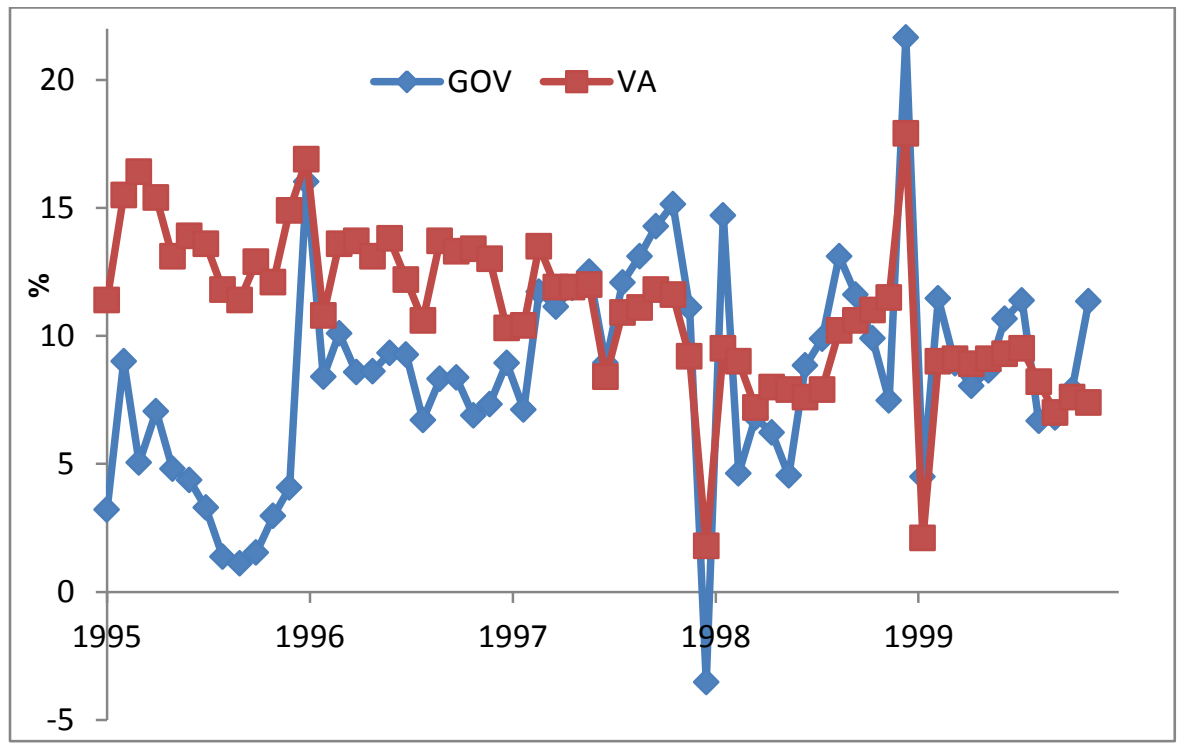

Figure 8. DRIE Real Growth Rates 1995-1999 


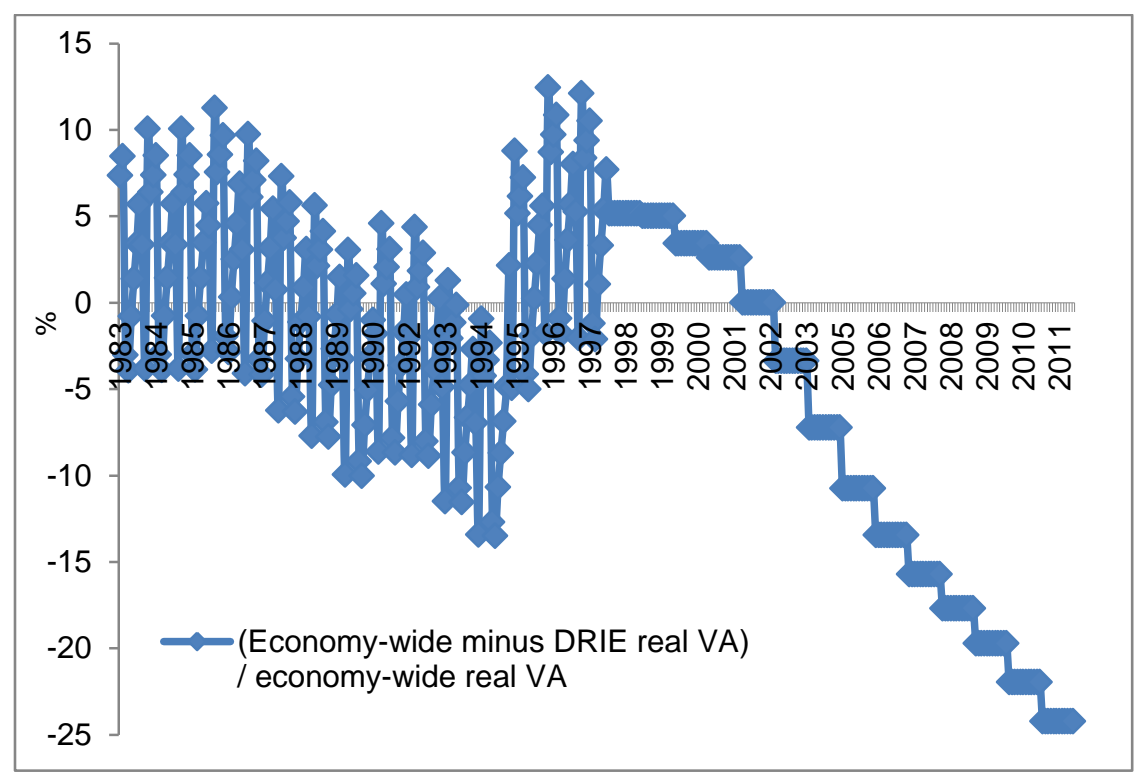

The values are based on the difference of two series, relative to the first series. The first series is economy-wide monthly real VA (based on annual real VA in 2002 prices, with the 2002 monthly nominal VA assumed to also be real values). The second series uses the same 2002 monthly anchor as the first series, and derives values for other months based on the DRIE yoy monthly real growth rate of output (constant price GOV through 1997, real VA growth rates since 1998). The (monthly) data in the chart run from May 1983 through 2011.

The different patterns up through 1997 and since 1998 are due to the way in which the series are constructed. The following provides a clue as to what is happening. Both series start with 2002 real VA: the second one with DRIE monthly real VA (taken to equal monthly nominal VA), the first one with economy-wide annual real VA that is broken down into monthly values using the monthly shares (in the summed monthly, 2002 value) inherent in the second series; i.e., the values of each month in 2002 of the first series is a (2002, one) fixed multiple of the value of each month of the second series. Other post1997 monthly values for the second series are constructed by applying the yoy monthly real growth rates; the resulting monthly, post-1997 real values also provide the monthly shares for the first series. The first series relies on annual real VA that is broken down into monthly values using the monthly shares inherent in the second series. The combination of annual real VA in the first series with the proportions inherent in the second year (with in 2002 up to a scalar identical monthly values) translates into year-specific (rather than month-specific) differences in the yoy monthly real growth rates of the two series. Going back in time, this changes in 1997, when constant price GOV proportions are applied to the annual real value in the first series, while the second series relies on 1998 real values and 1998 vs. 1997 real growth rates of DRIE VA (before switching to constant price GOV real growth rates starting with the 1996 real values). The choice of switching year does not matter; the discrepancy between the pattern inherent in one year's monthly constant price GOV (first series) vs. the pattern inherent in yoy monthly growth rates (second series) causes the regularity with one series being a fixed multiple of the other across all months of a year to break.

\section{Figure 9. Relative Difference between Economy-wide and DRIE Real Growth Rates}




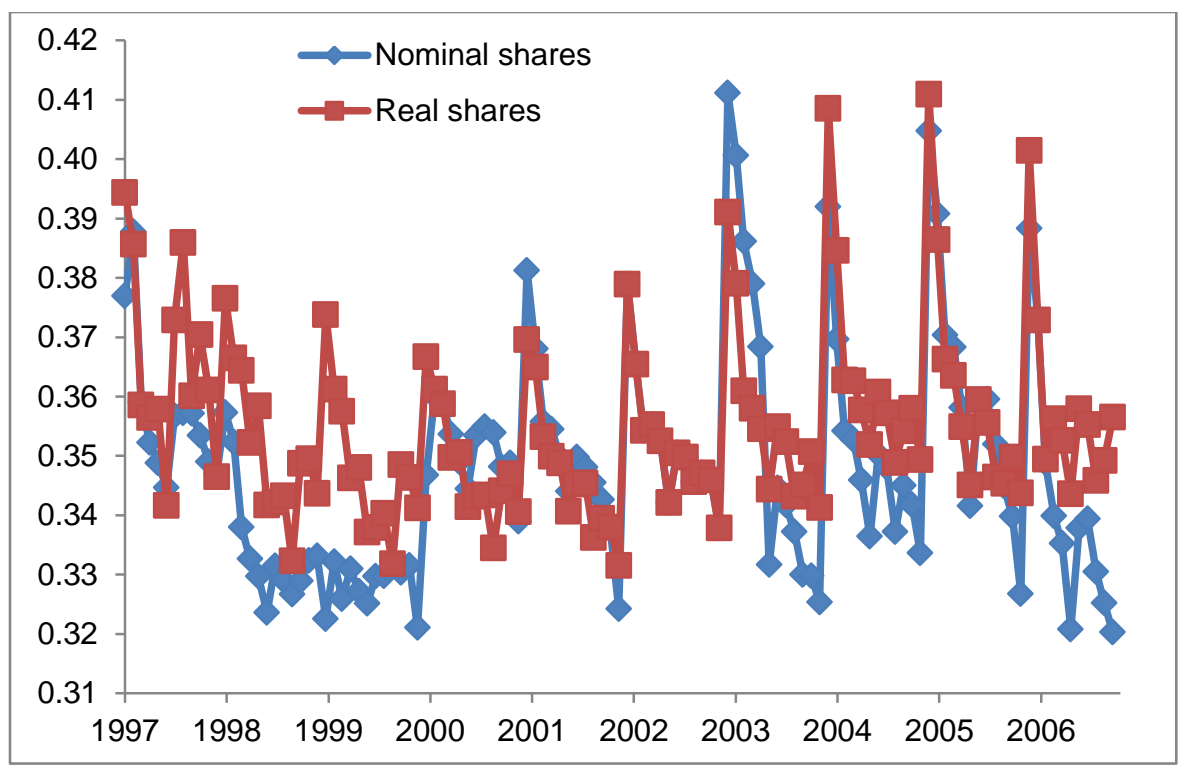

Nominal shares: Published nominal monthly SOSCE VA divided by derived nominal monthly economywide VA. Real shares: Derived monthly SOSCE real VA in 2002 prices divided by derived monthly economy-wide real VA in 2002 prices. 2002 shares are identical for the two series by construction (2002 nominal values are taken to be real values, too).

Figure 10. Monthly SOSCE Shares in Economy-wide VA

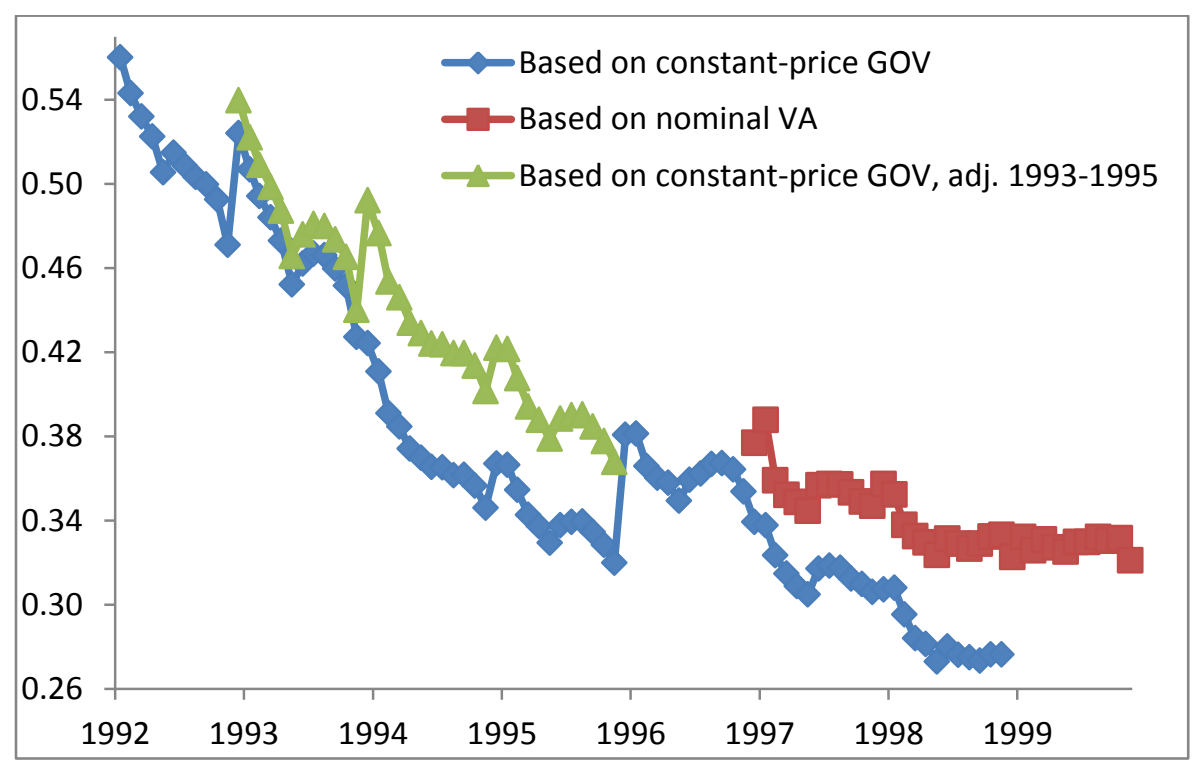

The constant price GOV series is the ratio (a)/(b), where (a) applies the monthly distribution of DRIE constant price GOV to break down economy-wide annual nominal GOV into monthly values, and (b) applies the monthly distribution of SOSCE constant price GOV to break down annual nominal SOSCE GOV into monthly values. Constant price data are in 1980 and 1990 prices; SOSCE value of 1993-1995 are adjusted SOE values. The nominal VA series is published monthly SOSCE nominal VA divided by the above derived monthly economy-wide nominal VA. The third series adjusts the second series in 19931995 by a multiplication factor. The multiplication factor is the ratio of (earlier derived) SOSCE monthly constant price GOV to SOE monthly constant price GOV.

Figure 11. Monthly SOSCE Shares in Economy-wide VA (Adjusted 1993-1995 Values) 
Table 1. Availability of Monthly Data Across Different Sources

\begin{tabular}{|c|c|c|}
\hline DRIEs & SOSCEs & SOEs \\
\hline \multicolumn{3}{|l|}{ Nominal GOV } \\
\hline Max: $10 / 93-12 / 98,1 / 03-12 / 11$ & & Max: $10 / 93-12 / 98,1 / 03-12 / 11$ \\
\hline $\begin{array}{l}\text { (2) } 11+12 / 90,10 / 93-6 / 98 \mathrm{~m}, \mathrm{c} \text { (incl. } \\
\text { growth rates) }\end{array}$ & & $\begin{array}{l}\text { (2) } 11+12 / 90,10 / 93-6 / 98 \mathrm{~m}, \mathrm{c} \\
\text { (incl. growth rates) }\end{array}$ \\
\hline $\begin{array}{l}\text { (5) } 3 / 92-12 / 98,1 / 03-12 / 11 \mathrm{~m}(12 / 02- \\
12 / 11 \mathrm{c})\end{array}$ & & $\begin{array}{l}\text { (5) } 3 / 92-12 / 98,1 / 03-12 / 11 \mathrm{~m} \\
\text { (probably "pure" SOEs) }\end{array}$ \\
\hline \multicolumn{3}{|l|}{ Constant price $G O V$} \\
\hline Max: 5/83-6/00, 1/03-12/11 & Max: 1/97-12/98 & Max: 5/83-12/98 \\
\hline (1) $5 / 83-2 / 00 \mathrm{~m} \mathrm{(1980} \mathrm{prices} \mathrm{through}$ & (1) $1 / 97-12 / 98 \mathrm{~m}$ (in '90 & (1) $5 / 83-12 / 98 \mathrm{~m}$ (1980 prices \\
\hline 1990, then 1990 prices) & prices) & through 1990, then 1990 \\
\hline (2) $11 / 90-9 / 93 \mathrm{~m}, \mathrm{c}$ ZGT; also c & & prices) \\
\hline growth rates & & (2) $11 / 90-9 / 93 \mathrm{~m}, \mathrm{c}$; also c \\
\hline (5) $1 / 86-12 / 90 \mathrm{~m}$ (1980 prices) & & growth rates \\
\hline (5) $1 / 91-6 / 00 \mathrm{~m}$ (1990 prices) & & (5) $1 / 86-12 / 90 \mathrm{~m}$ (1980 prices) \\
\hline $\begin{array}{l}\text { (5) } 1 / 95-6 / 00 \mathrm{~m} \mathrm{c}(-2 / 00) \text { growth } \\
\text { rates, } 1 / 03-12 / 11 \mathrm{~m} \text { c growth rates }\end{array}$ & & (5) $1 / 91-12 / 98 \mathrm{~m}$ (1990 prices) \\
\hline \multicolumn{3}{|l|}{ Nominal VA } \\
\hline Max: $1 / 94-11 / 06$ & Max: 1/97-11/06 & Max: $1 / 97-12 / 98$ \\
\hline (1) $1 / 99-11 / 06 \mathrm{~m}, \mathrm{c}$ (c value $12 / 06$ not & (1) $1 / 99-11 / 06 \mathrm{~m}, \mathrm{c}$ & (2) $7-11 / 98 \mathrm{~m}, \mathrm{c}$ \\
\hline plausible) & (2) $11 / 98-11 / 06 \mathrm{~m}, \mathrm{c}$ & (3) $1 / 97-12 / 98 \mathrm{~m}$ \\
\hline (2) $7 / 98-11 / 06 \mathrm{~m}, \mathrm{c}$ & (3) $1 / 97-11 / 06 \mathrm{~m}$ & \\
\hline (3) $1 / 94-11 / 06$ m (incomplete 1994) & (4) $1 / 01-11 / 06 \mathrm{~m}, \mathrm{c}$ & \\
\hline (4) $1 / 01-11 / 06 \mathrm{~m}, \mathrm{c}$ & (5) $5 / 94-11 / 06 \mathrm{~m}, \mathrm{c}(-12 / 06)$ & \\
\hline \multicolumn{3}{|l|}{ (5) $5 / 94-11 / 06 \mathrm{~m}, \mathrm{c}(-12 / 06)$} \\
\hline \multicolumn{3}{|l|}{ VA real growth rates (yoy) } \\
\hline Max: $5 / 94-12 / 11$ & Max: 1/97-12/11 & Max: 1/97-12/98 \\
\hline (1) $1 / 99-12 / 11 \mathrm{~m}, \mathrm{c}$ & (1) $1 / 99-12 / 11 \mathrm{~m}$ & (2) $7-11 / 98 \mathrm{c}$ \\
\hline (2) $7 / 98-12 / 11 \mathrm{c}$ & (2) $11 / 98-12 / 11 \mathrm{c}$ (also $\mathrm{m}$ & (3) $1 / 97-12 / 98 \mathrm{~m}$ \\
\hline (3) 5/94-12/11 m (incomplete 1994) & $3 / 07-)$ & \\
\hline (4) $7 / 98-12 / 11 \mathrm{~m}, \mathrm{c}$ & (3) $1 / 97-12 / 11 \mathrm{~m}$ & \\
\hline (5) $1 / 95-12 / 11 \mathrm{~m}(9 / 97-12 / 11 \mathrm{c})$ & (4) $7 / 98-12 / 11 \mathrm{~m}, \mathrm{c}$ & \\
\hline $\begin{array}{l}\text { (5) mom seasonally adjusted 9/09- } \\
12 / 11 \mathrm{~m} \text { (missing values }-2010 \text { ) }\end{array}$ & $\begin{array}{l}\text { (5) } 8 / 98-12 / 11 \mathrm{~m} \mathrm{(1/99-12/11} \\
\text { c) }\end{array}$ & \\
\hline
\end{tabular}

\section{Nominal sales value*}

Max: 3/92-12/11

(1) $2 / 07-12 / 11 \mathrm{~m}, \mathrm{c} * *$ (no January values)

(2) $10 / 93-10 / 98 \mathrm{~m}, \mathrm{c}$

(5) $3 / 92-12 / 11 \mathrm{~m}$

\section{Sales value [de facto: nominal] growth rates (yoy)}

Max: 10/93-12/11

(1) $2 / 07-12 / 11 \mathrm{~m}, \mathrm{c}$ (no January values)

(2) $10 / 93-10 / 98 \mathrm{c} * * *$

(5) $1 / 95-12 / 11 \mathrm{~m}$
Max: 2/07-12/11

(1) $2 / 07-12 / 11 \mathrm{~m}, \mathrm{c} * *$ (no January values)
Max: $3 / 92-12 / 11$

(1) $2 / 07-12 / 11 \mathrm{~m}, \mathrm{c} * *$ (no January values)

(2) $10 / 93-10 / 98 \mathrm{~m}, \mathrm{c}$

(5) $3 / 92-12 / 11 \mathrm{~m}$

Abbreviations: m: monthly, c: cumulative monthly, yoy: year-on-year, mom: month-on-month. Sources: (1) 3 magazines; (2) China Statistics; (3) People's Bank of China Quarterly Statistical Bulletin; (4) NBS (website); (5) CEIC. 
The most recent date for which the sources were checked is December 2011 (12/11). The same type of data are likely to be published in these sources in later months, too.

The SOE column reflects guoyou qiye, which could be either the unreformed (traditional, pure) SOEs only, or the sum of unreformed SOEs, SOE-SOE joint operation enterprises, and solely state-owned limited liability companies. The sources do not make this clear. Double-checks could occasionally be pursued against more elaborate annual data. If, in recent years, the SOE value is only a small fraction of the SOSCE value (say, one-fifth), "SOEs" in this source likely means the unreformed SOEs only.

In working with the data, a very few obvious typos were corrected. Different sources may at times report slightly different values. For example, constant price GOV in sources (1) and (5) differ by small amounts in a few months. Often, such differences cannot be reconciled. January data are sometimes not available but can then typically be backed out from monthly and cumulative monthly February data.

Occasional differences between the values provided by CEIC vs. other sources typically hint at data errors in the CEIC database. Thus, for example, the SOSCE VA values reported by CEIC for August through October 1998 match the SOE (not SOSCE) values published in the PBC Quarterly Statistical Bulletin. (Starting November 1988, the CEIC SOSCE values match the SOSCE values in the PBC Quarterly Statistical Bulletin). GOV values reported in the 3 magazines vs. CEIC for April 1986, February 1988, and May 1994 are 73.96 b vs. 78.96 b yuan, 78.19 vs. $78.91 b$ yuan, and 364.26 vs. $368.26 \mathrm{~b}$ yuan, i.e., one digit differs in each of these instances; presumably the CEIC database relies on the 3 magazines for its data, rather than the CEIC somehow obtaining correct data from the NBS while the NBS in its publications (over several issues) continuously published one and the same erroneous data point.

* The labeling varies across sources. CEIC calls this series "industrial sales" (gongye xiaoshou). Labels encountered in other sources include "industrial sales value" (gongye xiaoshou chanzhi) and "industrial sales volume value" (gongye xiaoshou chanliang zhi). The SOSCE category is labeled "state share-holding" in the source, which could suggest the difference between SOSCEs and SOEs; comparing the summed monthly "state share-holding" value of 2010 to the annual SOSCE value (published in the Industrial Yearbook 2011, p. 106) yields two near-identical figures (18,160.9b yuan vs. 18,359.117b yuan), implying that these monthly values are SOSCE values.

** Monthly and cumulative monthly values are never fully consistent. (I.e., this month's cumulative value less the previous month's cumulative value is not identical to this month's value, though very close.)

*** Early sources do not specify if these are nominal or real growth rates. In the magazine China Monthly Statistics in the late 2000s and early 2010s, the reported growth rates are explicitly marked as being at current prices. These published growth rates do not perfectly match the growth rates implicit in the nominal values; they come close. 
Table 2 Summed Monthly (Annual) Absolute Percentage Differences in DRIE Monthly Output Distributions*

\begin{tabular}{|c|c|c|c|c|c|c|c|c|c|c|}
\hline Series 1 & VA & VA & VA & VA & VA & VA & VA & GOV & GOV & GOV \\
\hline Availability: & $\begin{array}{l}\text { nominal } \\
\text { '95- } 06\end{array}$ & $\begin{array}{l}\text { nominal } \\
\text { '95-'06 }\end{array}$ & $\begin{array}{l}\text { nomina } \\
' 95-06\end{array}$ & $\begin{array}{l}\text { nominal } \\
\text { '95- ‘06 }\end{array}$ & $\begin{array}{l}\text { real } \\
94-' 11\end{array}$ & $\begin{array}{l}\text { real } \\
94-' 11\end{array}$ & $\begin{array}{l}\text { real } \\
94-' 11\end{array}$ & $\begin{array}{c}\text { nominal } \\
\text { '93- '98,' } \\
03-11\end{array}$ & $\begin{array}{c}\text { nominal } \\
\text { '93-'98,' } \\
03-11\end{array}$ & $\begin{array}{c}\text { real } \\
\text { '05/83- } \\
999\end{array}$ \\
\hline Series 2 & $\begin{array}{l}\text { VA } \\
\text { real }\end{array}$ & $\begin{array}{c}\text { GOV } \\
\text { nominal }\end{array}$ & $\begin{array}{c}\text { GOV } \\
\text { real }\end{array}$ & $\begin{array}{c}\text { Sales } \\
\text { nominal }\end{array}$ & $\begin{array}{c}\text { GOV } \\
\text { nominal }\end{array}$ & $\begin{array}{c}\text { GOV } \\
\text { real }\end{array}$ & $\begin{array}{c}\text { Sales } \\
\text { nominal }\end{array}$ & $\begin{array}{c}\text { GOV } \\
\text { real }\end{array}$ & $\begin{array}{c}\text { Sales } \\
\text { nominal }\end{array}$ & $\begin{array}{c}\text { Sales } \\
\text { nominal }\end{array}$ \\
\hline 1993 & & & & & & & & 2.4 & 3.0 & 4.4 \\
\hline 1994 & & & & & 4.9 & 4.4 & 5.6 & 2.2 & 2.7 & 4.7 \\
\hline 1995 & 5.2 & 2.6 & 2.5 & 3.9 & 4.2 & 4.4 & 4.8 & 1.2 & 1.7 & 2.4 \\
\hline 1996 & 5.1 & 2.4 & 2.6 & 3.8 & 4.1 & 4.4 & 4.1 & 0.7 & 2.0 & 1.9 \\
\hline 1997 & 4.3 & 1.0 & 2.1 & 2.3 & 3.5 & 3.9 & 3.8 & 1.4 & 1.6 & 1.8 \\
\hline 1998 & 3.6 & 0.5 & 2.9 & 1.9 & 3.2 & 2.2 & 2.5 & 2.4 & 1.6 & 2.0 \\
\hline 1999 & 2.4 & & 1.1 & 7.4 & & 2.2 & 7.1 & & & 7.1 \\
\hline 2000 & 1.1 & & & 1.1 & & & 1.3 & & & \\
\hline 2001 & 2.7 & & & 1.0 & & & 2.4 & & & \\
\hline 2002 & (a) 0.0 & & & 1.2 & & & 1.2 & & & \\
\hline 2003 & 2.0 & 1.6 & & 1.0 & 0.9 & & 1.7 & & 0.9 & \\
\hline 2004 & 1.4 & 0.7 & & 1.0 & 1.2 & & 1.9 & & 0.9 & \\
\hline 2005 & 2.2 & 1.5 & & 1.8 & 1.5 & & 1.6 & & 0.8 & \\
\hline 2006 & 1.9 & 2.5 & & 1.1 & 3.0 & & 2.0 & & 2.2 & \\
\hline 2007 & & & & & 1.9 & & 2.2 & & 0.5 & \\
\hline 2008 & & & & & 3.5 & & 3.4 & & 0.3 & \\
\hline 2009 & & & & & 3.2 & & 3.6 & & 0.4 & \\
\hline 2010 & & & & & 2.8 & & 3.0 & & 0.4 & \\
\hline 2011 & & & & & 2.4 & & 2.3 & & 0.3 & \\
\hline Ave 95-98 & 4.5 & 1.6 & 2.5 & 3.0 & 3.7 & 3.7 & 3.8 & 1.4 & 1.7 & 2.0 \\
\hline Ave 03-06 & 1.9 & 1.6 & & 1.2 & 1.7 & & 1.8 & & 1.2 & \\
\hline
\end{tabular}

* The value 5.2 in the row labeled ' 1995 ' and the column with Series 1 "VA nominal" and Series 2 "VA real" means the sum across the twelve months of 1995 of each month's absolute difference between (i) this month's share in annual (summed monthly) nominal VA of the DRIEs (in percent) and (ii) this month's share in annual (summed monthly) real VA of the DRIEs (in percent).

(a) The value is zero by design: real monthly 2002 VA was set equal to nominal monthly 2002 VA.

Real GOV: GOV in 1990 prices; real VA: VA in 2002 prices. Nominal sales value data are available for the complete years 1993-2011.

The two rows of average values at the bottom report the average annual absolute difference in the period specified. 
Appendix 1. Final Monthly Value-added Series (b yuan)

\begin{tabular}{|c|c|c|c|c|c|c|c|c|c|c|c|c|}
\hline \multirow[b]{3}{*}{ Month } & \multicolumn{6}{|c|}{ May 1983 - December 1997} & \multicolumn{6}{|c|}{ January 1998 - December 2011} \\
\hline & & \multicolumn{3}{|c|}{ Economy-wide } & \multicolumn{2}{|c|}{ SOSCES } & \multicolumn{4}{|c|}{ Economy-wide } & \multicolumn{2}{|l|}{ SOSCEs } \\
\hline & Year & $\begin{array}{l}\text { in } \\
2002 \\
\text { con- } \\
\text { stant } \\
\text { prices }\end{array}$ & $\begin{array}{l}\text { Ref.: in } \\
2002 \\
\text { prices } \\
\text { via } \\
\text { DRIE } \\
\text { real } \\
\text { growth }\end{array}$ & $\begin{array}{l}\text { in } \\
\text { current } \\
\text { prices }\end{array}$ & $\begin{array}{l}\text { in } \\
2002 \\
\text { con- } \\
\text { stant } \\
\text { prices }\end{array}$ & $\begin{array}{l}\text { in } \\
\text { current } \\
\text { prices }\end{array}$ & Year & $\begin{array}{l}\text { in } 2002 \\
\text { con-stant } \\
\text { prices }\end{array}$ & $\begin{array}{l}\text { Ref.: in } \\
2002 \\
\text { prices } \\
\text { via } \\
\text { DRIE } \\
\text { real } \\
\text { growth }\end{array}$ & $\begin{array}{l}\text { in } \\
\text { current } \\
\text { prices }\end{array}$ & $\begin{array}{l}\text { in } \\
2002 \text { con- } \\
\text { stant prices }\end{array}$ & $\begin{array}{l}\text { in } \\
\text { current } \\
\text { prices }\end{array}$ \\
\hline May & 1983 & 44.26 & 41.22 & 20.50 & 29.01 & 14.80 & & & & & & \\
\hline June & 1983 & 44.85 & 41.34 & 20.77 & 28.14 & 14.81 & & & & & & \\
\hline July & 1983 & 41.22 & 42.51 & 19.09 & 27.50 & 13.74 & & & & & & \\
\hline Aug & 1983 & 42.05 & 43.77 & 19.48 & 28.63 & 14.01 & & & & & & \\
\hline Sept & 1983 & 45.10 & 45.46 & 20.89 & 28.84 & 15.12 & & & & & & \\
\hline$O c t$ & 1983 & 44.99 & 44.37 & 20.84 & 30.26 & 15.22 & & & & & & \\
\hline Nov & 1983 & 46.33 & 44.80 & 21.46 & 30.96 & 15.73 & & & & & & \\
\hline Dec & 1983 & 45.10 & 42.67 & 20.89 & 28.23 & 14.97 & & & & & & \\
\hline Jan & 1984 & 45.06 & 43.60 & 21.33 & 29.79 & 15.53 & 1998 & 219.48 & 208.71 & 233.98 & 82.64 & 83.60 \\
\hline $\mathrm{Feb}$ & 1984 & 39.73 & 41.31 & 18.81 & 26.21 & 13.91 & 1998 & 213.13 & 202.67 & 229.90 & 78.11 & 81.00 \\
\hline March & 1984 & 49.25 & 44.74 & 23.31 & 31.60 & 16.50 & 1998 & 256.61 & 244.03 & 284.92 & 93.50 & 96.30 \\
\hline April & 1984 & 48.56 & 45.64 & 22.99 & 28.65 & 15.90 & 1998 & 267.93 & 254.79 & 282.88 & 94.38 & 94.10 \\
\hline May & 1984 & 49.57 & 46.15 & 23.46 & 31.54 & 16.25 & 1998 & 274.45 & 260.99 & 285.43 & 98.37 & 94.10 \\
\hline June & 1984 & 49.78 & 45.88 & 23.57 & 30.47 & 16.20 & 1998 & 290.75 & 276.49 & 298.84 & 99.35 & 96.70 \\
\hline July & 1984 & 47.08 & 48.54 & 22.29 & 30.47 & 15.38 & 1998 & 270.63 & 257.36 & 263.69 & 92.61 & 87.40 \\
\hline Aug & 1984 & 48.21 & 50.16 & 22.82 & 31.77 & 15.71 & 1998 & 277.32 & 263.72 & 268.62 & 95.20 & 88.40 \\
\hline Sept & 1984 & 51.62 & 52.01 & 24.43 & 31.69 & 16.77 & 1998 & 296.39 & 281.85 & 293.58 & 98.48 & 95.90 \\
\hline$O c t$ & 1984 & 51.80 & 51.07 & 24.52 & 32.82 & 16.67 & 1998 & 302.74 & 287.89 & 303.08 & 105.58 & 99.70 \\
\hline Nov & 1984 & 54.14 & 52.33 & 25.63 & 33.50 & 17.18 & 1998 & 317.78 & 302.19 & 314.12 & 111.06 & 104.40 \\
\hline Dec & 1984 & 54.36 & 51.41 & 25.73 & 31.31 & 16.76 & 1998 & 344.06 & 327.19 & 342.82 & 118.25 & 114.20 \\
\hline Jan & 1985 & 56.11 & 54.29 & 27.79 & 34.86 & 18.80 & 1999 & 258.42 & 246.07 & 262.58 & 96.61 & 84.70 \\
\hline $\mathrm{Feb}$ & 1985 & 48.48 & 50.41 & 24.01 & 29.56 & 16.23 & 1999 & 217.31 & 206.93 & 223.08 & 78.50 & 74.10 \\
\hline March & 1985 & 60.25 & 54.74 & 29.84 & 36.44 & 19.69 & 1999 & 279.34 & 265.99 & 290.59 & 99.86 & 94.70 \\
\hline April & 1985 & 60.61 & 56.96 & 30.02 & 33.43 & 19.20 & 1999 & 291.92 & 277.97 & 295.82 & 101.08 & 97.90 \\
\hline May & 1985 & 60.75 & 56.56 & 30.09 & 36.04 & 19.21 & 1999 & 298.48 & 284.22 & 298.60 & 103.88 & 97.70 \\
\hline June & 1985 & 61.18 & 56.38 & 30.30 & 34.89 & 19.19 & 1999 & 316.78 & 301.65 & 316.17 & 106.81 & 102.80 \\
\hline July & 1985 & 56.59 & 58.34 & 28.03 & 34.40 & 17.97 & 1999 & 295.40 & 281.29 & 282.07 & 99.83 & 93.00 \\
\hline Aug & 1985 & 56.60 & 58.88 & 28.03 & 35.30 & 18.06 & 1999 & 303.27 & 288.78 & 289.90 & 103.19 & 95.60 \\
\hline Sept & 1985 & 59.11 & 59.56 & 29.28 & 34.64 & 18.97 & 1999 & 320.27 & 304.96 & 306.43 & 106.26 & 101.80 \\
\hline$O c t$ & 1985 & 57.86 & 57.04 & 28.65 & 35.34 & 18.58 & 1999 & 323.50 & 308.04 & 316.35 & 112.76 & 104.50 \\
\hline Nov & 1985 & 58.89 & 56.91 & 29.16 & 35.63 & 18.91 & 1999 & 341.47 & 325.16 & 333.92 & 118.28 & 110.70 \\
\hline
\end{tabular}




\begin{tabular}{|c|c|c|c|c|c|c|c|c|c|c|c|c|}
\hline Dec & 1985 & .93 & 6.67 & 68 & 34.19 & 18.94 & 1999 & 369.03 & 351.40 & 370.64 & 125.93 & 119.00 \\
\hline Jan & 1986 & 9.89 & 7.33 & 11 & 36.27 & 20.26 & 2000 & 277.15 & 67.97 & 277.71 & & 96.30 \\
\hline$e b$ & 1986 & 9.46 & & & & & 2000 & & & & & 0.50 \\
\hline Iarch & 1986 & 4.57 & & & & & 2000 & & & & & 4.10 \\
\hline pril & 1986 & 3.64 & & & & 20.56 & 2000 & & & & & 5.30 \\
\hline May & 1986 & 4.50 & 59.42 & & & 20.86 & 2000 & & .91 & & & 5.80 \\
\hline une & 1986 & 6.13 & 60.29 & 4.35 & 36.99 & 21.07 & 2000 & 350.03 & 338.45 & & & 121.80 \\
\hline uly & 1986 & 0.58 & 61.78 & 1.46 & 36.12 & 19.54 & 2000 & 328.15 & 17.29 & & 12.61 & 17.10 \\
\hline$u g$ & 1986 & 2.18 & 64.01 & 2.29 & 7.81 & 20.02 & 2000 & 336.89 & 5.74 & & & 0.70 \\
\hline ept & 1986 & 5.97 & 65. & & & & 2000 & & & & & 5.20 \\
\hline$D_{c t}$ & 1986 & 66.72 & 65. & & & 21.26 & 2000 & & & & & 3.30 \\
\hline ov & 1986 & 69.10 & 66.07 & 39 & & 21.96 & 2000 & 371.93 & 63 & & .04 & 28.00 \\
\hline$e c$ & 1986 & 71.05 & 66. & & & .99 & 2000 & 1.22 & & & & 135.10 \\
\hline an & 1987 & 62.47 & 60. & & & 20.82 & 2001 & & & & & 104.50 \\
\hline$e b$ & 1987 & 0.34 & 62. & & & 19.95 & 2001 & & & & & 5.10 \\
\hline Iarch & 1987 & 72.50 & 66.06 & & & 23.42 & 2001 & & & & & 3.80 \\
\hline pril & 1987 & 72.30 & 68. & & & & 2001 & & & & & .90 \\
\hline Iay & 1987 & 73.24 & 68.39 & & & & 2001 & & & & & 128.90 \\
\hline une & 1987 & 76.22 & 70.44 & & & & 2001 & 382.39 & & & & 33.40 \\
\hline aly & & & & & & & & & & & & \\
\hline$u g$ & 1987 & 70.90 & & & & & 2001 & & & & & \\
\hline ept & 1987 & & & & & & 2001 & & & & & \\
\hline$\partial c t$ & 1987 & 75.53 & 74.68 & 40.06 & & 23.67 & 2001 & 383.13 & & & & 129.20 \\
\hline Iov & 1987 & 76.92 & 74.56 & & & 23.97 & 2001 & 3.19 & & & & 30.40 \\
\hline$e c$ & 1987 & 78.98 & 74.91 & & & & 2001 & & & & & 38.00 \\
\hline an & 1988 & 76.33 & 75.75 & & & 26.53 & 2002 & .13 & & & & 23.20 \\
\hline$e b$ & 1988 & 65.71 & 70.08 & & & 23.03 & 2002 & 283.24 & & & & 03.50 \\
\hline Iarch & 1988 & 81.22 & 75.69 & 47. & & 27.63 & 2002 & 370.03 & .03 & & & 1.10 \\
\hline pril & 1988 & 82.88 & 79.90 & 48.04 & 43.46 & 27.45 & 2002 & 387.05 & 7.05 & .05 & .50 & 137.50 \\
\hline May & 1988 & 84.44 & 80.65 & 48.95 & & 27.74 & 2002 & 394.28 & 394.28 & .28 & & 39.00 \\
\hline une & 1988 & 87.69 & & & & & 2002 & & & & & 3.30 \\
\hline uly & 1988 & 3.88 & & & & & 2002 & & & & & 135.60 \\
\hline$u g$ & 1988 & 82.00 & 87.52 & & & 26.60 & 2002 & & & & & 138.80 \\
\hline Sept & 1988 & 88.52 & & & & 28.67 & 2002 & & & & & 147.10 \\
\hline$D_{c t}$ & 1988 & & & & & & 2002 & & & & & 148.00 \\
\hline ov & 1988 & 88.70 & & & & 28.67 & 2002 & & & & & 153.70 \\
\hline Dec & 1988 & 91.34 & 88.61 & & & & 2002 & & & & & 163.70 \\
\hline Ian & 1989 & 81.26 & & & & & 2003 & & & & & 146.50 \\
\hline $\mathrm{Feb}$ & 1989 & 69.54 & 75.34 & 43.07 & & 25.03 & 2003 & 327.92 & 339.33 & 340.96 & & 136.60 \\
\hline March & 1989 & 91.78 & 86.88 & 56.84 & 50.88 & 32.28 & 2003 & 418.02 & 432.56 & 419.54 & 150.90 & 162.00 \\
\hline April & 1989 & 92.77 & 90.85 & 57.45 & 47.21 & 31.84 & 2003 & 429.77 & 444.72 & 427.97 & 153.86 & 162.20 \\
\hline
\end{tabular}




\begin{tabular}{|c|c|c|c|c|c|c|c|c|c|c|c|c|}
\hline May & 1989 & 92.38 & 89.63 & 57.21 & 50.61 & 31.68 & 2003 & 433.23 & 448.30 & 427.03 & 153.60 & 157.30 \\
\hline June & 1989 & 93.92 & 90.19 & 58.17 & 49.09 & 31.71 & 2003 & 473.16 & 489.62 & 486.34 & 162.93 & 161.30 \\
\hline July & 1989 & 85.07 & 91.37 & 52.68 & 47.79 & 29.31 & 2003 & 435.58 & 450.74 & 456.48 & 154.58 & 157.30 \\
\hline Aug & 1989 & 85.67 & 92.88 & 53.06 & 49.39 & 29.67 & 2003 & 449.08 & 464.70 & 468.26 & 158.23 & 160.00 \\
\hline Sept & 1989 & 87.94 & 92.33 & 54.46 & 47.74 & 30.70 & 2003 & 478.35 & 495.00 & 495.84 & 164.16 & 167.20 \\
\hline$O c t$ & 1989 & 85.65 & 87.99 & 53.04 & 48.33 & 29.83 & 2003 & 482.91 & 499.71 & 502.40 & 166.65 & 165.80 \\
\hline Nov & 1989 & 88.07 & 88.69 & 54.54 & 48.95 & 30.51 & 2003 & 506.22 & 523.83 & 530.91 & 177.52 & 175.10 \\
\hline Dec & 1989 & 92.95 & 91.60 & 57.56 & 48.68 & 31.66 & 2003 & 552.99 & 572.23 & 582.45 & 188.75 & 189.50 \\
\hline Jan & 1990 & 74.44 & 76.93 & 47.17 & 43.36 & 27.50 & 2004 & 371.20 & 400.12 & 405.12 & 151.64 & 158.80 \\
\hline $\mathrm{Feb}$ & 1990 & 71.62 & 79.55 & 45.39 & 40.42 & 26.09 & 2004 & 387.83 & 418.05 & 449.35 & 149.16 & 166.10 \\
\hline March & 1990 & 90.81 & 88.13 & 57.55 & 50.88 & 32.32 & 2004 & 479.14 & 516.48 & 516.65 & 173.83 & 183.00 \\
\hline April & 1990 & 92.29 & 92.65 & 58.49 & 47.55 & 32.11 & 2004 & 491.37 & 529.66 & 529.45 & 178.17 & 186.80 \\
\hline May & 1990 & 93.92 & 93.41 & 59.52 & 51.61 & 32.35 & 2004 & 488.67 & 526.75 & 522.07 & 174.79 & 180.60 \\
\hline June & 1990 & 96.99 & 95.48 & 61.47 & 50.44 & 32.63 & 2004 & 527.81 & 568.94 & 558.21 & 185.74 & 187.80 \\
\hline July & 1990 & 85.42 & 94.06 & 54.14 & 47.69 & 29.29 & 2004 & 482.97 & 520.60 & 534.12 & 174.22 & 187.10 \\
\hline Aug & 1990 & 87.43 & 97.17 & 55.41 & 49.97 & 30.05 & 2004 & 499.66 & 538.59 & 550.53 & 178.49 & 191.60 \\
\hline Sept & 1990 & 92.22 & 99.26 & 58.45 & 49.15 & 31.65 & 2004 & 533.14 & 574.69 & 582.98 & 186.00 & 196.60 \\
\hline$O c t$ & 1990 & 94.13 & 99.13 & 59.65 & 52.01 & 32.15 & 2004 & 536.37 & 578.16 & 591.80 & 189.98 & 204.20 \\
\hline Nov & 1990 & 98.76 & 101.96 & 62.59 & 53.59 & 33.44 & 2004 & 557.89 & 601.36 & 615.87 & 199.71 & 210.50 \\
\hline Dec & 1990 & 104 & 105.17 & & & 35.05 & 2004 & & 654.63 & & 12.15 & 21.80 \\
\hline Jan & 1991 & 93.44 & 95.15 & 61.04 & & 36.08 & 2005 & & & 536.84 & 177.42 & 217.30 \\
\hline $\mathrm{Feb}$ & 1991 & 78.98 & 86.43 & 51.59 & 42.82 & 30.71 & 2005 & 401.47 & & 471.64 & 155.13 & 184.30 \\
\hline March & 1991 & 100.68 & 96.27 & 65.77 & 51.37 & 37.94 & 2005 & 530.57 & 594.46 & 594.84 & 194.34 & 220.30 \\
\hline April & 1991 & 104.71 & 103.57 & 68.41 & 53.31 & 38.54 & 2005 & 548.37 & 614.41 & 625.82 & 199.38 & 230.50 \\
\hline May & 1991 & 108.11 & 105.94 & 70.63 & 55.86 & 39.47 & 2005 & 548.18 & 614.19 & 631.93 & 194.54 & 226.30 \\
\hline June & 1991 & 111.80 & 108.43 & 73.03 & 54.93 & 40.13 & 2005 & 593.10 & 664.52 & 686.21 & 204.69 & 234.40 \\
\hline July & 1991 & 98.68 & 107.06 & 64.46 & 52.52 & 36.58 & 2005 & 539.45 & 604.42 & 644.05 & 193.90 & 231.50 \\
\hline Aug & 1991 & 101.79 & 111.46 & 66.49 & 55.21 & 37.31 & 2005 & 557.61 & 624.77 & 661.40 & 198.30 & 237.80 \\
\hline Sept & 1991 & 107.50 & 114.00 & 70.23 & 54.44 & 39.30 & 2005 & 597.55 & 669.51 & 695.51 & 207.02 & 244.80 \\
\hline$O c t$ & 1991 & 108.72 & 112.81 & 71.02 & 56.90 & 39.28 & 2005 & 599.10 & 671.25 & 700.46 & 206.89 & 241.60 \\
\hline Nov & 1991 & 110.00 & 111.88 & 71.86 & 55.94 & 39.29 & 2005 & 625.82 & 701.18 & 730.41 & 218.89 & 248.20 \\
\hline Dec & 1991 & 113.55 & 113.02 & 74.18 & 54.78 & 39.61 & 2005 & 680.67 & 762.64 & 743.96 & 234.00 & 243.10 \\
\hline Jan & 1992 & 105.26 & 107.41 & 72.17 & 55.67 & 40.43 & 2006 & 472.22 & 545.54 & 599.28 & 189.59 & 240.60 \\
\hline $\mathrm{Feb}$ & 1992 & 96.14 & 105.43 & 65.92 & 49.94 & 36.93 & 2006 & 467.63 & 540.24 & 581.58 & 174.37 & 216.86 \\
\hline March & 1992 & 120.67 & 115.62 & 82.74 & 58.99 & 44.93 & 2006 & 606.16 & 700.28 & 709.80 & 211.84 & 248.05 \\
\hline April & 1992 & 123.54 & 122.45 & 84.71 & 60.45 & 45.07 & 2006 & 620.12 & 716.40 & 724.69 & 220.91 & 258.16 \\
\hline May & 1992 & 125.89 & 123.62 & 86.32 & 61.91 & 45.11 & 2006 & 626.81 & 724.13 & 750.20 & 221.00 & 264.51 \\
\hline June & 1992 & 133.46 & 129.71 & 91.51 & 61.39 & 46.25 & 2006 & 687.38 & 794.11 & 830.74 & 236.21 & 285.47 \\
\hline July & 1992 & 121.37 & 131.96 & 83.22 & 59.65 & 42.84 & 2006 & 610.56 & 705.36 & 765.07 & 218.53 & 273.83 \\
\hline Aug & 1992 & 123.12 & 135.11 & 84.42 & 61.64 & 42.95 & 2006 & 625.70 & 722.85 & 781.61 & 222.29 & 277.68 \\
\hline Sept & 1992 & 129.49 & 137.62 & 88.79 & 60.03 & 44.69 & 2006 & 672.84 & 777.30 & 823.97 & 232.68 & 284.95 \\
\hline
\end{tabular}




\begin{tabular}{|c|c|c|c|c|c|c|c|c|c|c|c|c|}
\hline$O c t$ & 92 & & & & & .49 & 2006 & & & & & \\
\hline Iov & 1992 & 8.39 & & & & & 2006 & & & & & \\
\hline & & & & & & & 2006 & & & & & \\
\hline an & 1993 & & & & & & 2007 & & & & & \\
\hline & 1993 & & & & & & 2007 & & & & & \\
\hline Iarch & 1993 & 147.74 & & & & .25 & 2007 & & & & & 2.71 \\
\hline pril & 1993 & 150.18 & & & & .98 & 2007 & & & & & 7.36 \\
\hline May & 1993 & 155.60 & 157.43 & & & 9.72 & 2007 & & & & & 3.57 \\
\hline ine & 1993 & & & & & 86 & 2007 & & & & & \\
\hline ily & 1993 & 41 & 165 & 1 & & 5.28 & 2007 & & & & & .20 \\
\hline$u g$ & 1993 & & 56.73 & & & 86 & 2007 & & & & & 9.85 \\
\hline ept & 1993 & 49.73 & 63.94 & & & .61 & 2007 & & & & & .27 \\
\hline$c t$ & 1993 & 92 & 50.62 & & & 93 & 2007 & & & & .40 & .94 \\
\hline$o v$ & 1993 & & & & & & 2007 & & & & & .22 \\
\hline$e c$ & 1993 & & & & & .41 & 2007 & & & & & 7.63 \\
\hline an & 1994 & & & & & & 2008 & & & & & \\
\hline$e b$ & 1994 & & & & & & 2008 & & & & & \\
\hline Iarch & 1994 & & & & & & 2008 & & & & & \\
\hline pril & 1994 & & & & & & 2008 & & & & & 4.67 \\
\hline Iay & & & & & & & & & & & & \\
\hline une & 1994 & & & & & & 2008 & & & & & \\
\hline ıly & & & & & & & 2008 & & & & & \\
\hline$u g$ & 1994 & 174.41 & 201.61 & & & 67.21 & 2008 & & & & & 3.40 \\
\hline ept & 1994 & 184.45 & 206.49 & & & 0.36 & 2008 & & & & & 5.68 \\
\hline$c t$ & 1994 & 89.01 & 7.04 & & & 2.11 & 2008 & & & & & 7.27 \\
\hline Iov & 1994 & 200.08 & & & & 5.26 & 2008 & & & & & 2.13 \\
\hline Dec & 1994 & 225.05 & 236.47 & 204 & & .17 & 2008 & & & .22 & & 4.98 \\
\hline an & 1995 & 165.70 & .22 & 169.35 & & 71.48 & 2009 & & & & & .12 \\
\hline$e b$ & 1995 & 151.53 & 159.41 & 167.30 & .47 & 70.51 & 2009 & & 779.20 & .55 & .76 & 9.79 \\
\hline March & 1995 & 198.01 & 182.01 & 212.20 & 2 & 86.52 & 2009 & & & 4.28 & & 5.35 \\
\hline pril & 1995 & 207.15 & & & & & 2009 & & & & & .74 \\
\hline May & 1995 & & & & & & 2009 & & & 0.15 & & 65.21 \\
\hline une & 1995 & 223.43 & 208. & & & & 2009 & & & 1249.66 & & 6.45 \\
\hline uly & 1995 & & & & & & 2009 & & & & & 99.54 \\
\hline$u g$ & 1995 & & & & & & 2009 & & & & & 410.55 \\
\hline ept & 1995 & 204.76 & & & & & 2009 & & & & & 432.53 \\
\hline$c t$ & 1995 & & & & & 79.69 & 2009 & & & & & 423.55 \\
\hline Iov & 1995 & 226.21 & & & & & 2009 & & & & & \\
\hline Dec & 1995 & 257.17 & 246.09 & 255.87 & & 94.12 & 2009 & 1032.78 & 1286.31 & 1387.60 & & 500.31 \\
\hline Ian & 1996 & 198.72 & 188.19 & 225.96 & & 86.01 & 2010 & & & 1082.80 & 309.72 & 442.33 \\
\hline $\mathrm{Feb}$ & 1996 & 169.78 & 172.79 & 194.12 & 66.98 & 74.02 & 2010 & & & & 251.26 & 345.76 \\
\hline
\end{tabular}




\begin{tabular}{|c|c|c|c|c|c|c|c|c|c|c|c|c|}
\hline March & 1996 & 225.35 & 200.40 & 245.44 & 82.79 & 89.77 & 2010 & 968.31 & 1240.80 & 1261.12 & 333.90 & 434.86 \\
\hline April & 1996 & 232.50 & 213.88 & 251.46 & 85.97 & 90.61 & 2010 & 959.87 & 1229.99 & 1282.48 & 334.84 & 447.38 \\
\hline May & 1996 & 237.03 & 216.02 & 253.94 & 89.06 & 90.88 & 2010 & 982.18 & 1258.57 & 1338.67 & 336.32 & 458.39 \\
\hline June & 1996 & 252.48 & 227.75 & 235.23 & 89.58 & 82.17 & 2010 & 1080.34 & 1384.36 & 1447.27 & 360.25 & 482.60 \\
\hline July & 1996 & 217.59 & 219.56 & 235.54 & 83.28 & 84.62 & 2010 & 936.09 & 1199.52 & 1316.53 & 328.85 & 462.49 \\
\hline Aug & 1996 & 214.13 & 218.08 & 232.30 & 85.18 & 84.16 & 2010 & 956.34 & 1225.46 & 1357.48 & 336.04 & 476.99 \\
\hline Sept & 1996 & 229.27 & 226.13 & 244.97 & 86.43 & 89.85 & 2010 & 1036.87 & 1328.65 & 1454.50 & 358.50 & 502.90 \\
\hline Oct & 1996 & 236.04 & 227.79 & 253.63 & 93.17 & 93.13 & 2010 & 1006.45 & 1289.68 & 1435.15 & 347.45 & 495.45 \\
\hline Nov & 1996 & 249.95 & 236.45 & 268.46 & 96.19 & 97.80 & 2010 & 1049.80 & 1345.23 & 1519.23 & 377.37 & 546.12 \\
\hline Dec & 1996 & 285.30 & 264.12 & 303.70 & 103.58 & 107.46 & 2010 & 1139.34 & 1459.96 & 1633.07 & 408.87 & 586.06 \\
\hline Jan & 1997 & 215.82 & 205.02 & 240.89 & 85.11 & 90.80 & 2011 & 834.04 & 1100.75 & 1270.57 & 342.86 & 522.32 \\
\hline $\mathrm{Feb}$ & 1997 & 181.30 & 185.09 & 200.90 & 69.93 & 77.90 & 2011 & 765.20 & 1009.90 & 1140.59 & 277.64 & 413.84 \\
\hline March & 1997 & 250.98 & 223.88 & 276.54 & 89.99 & 99.30 & 2011 & 1079.29 & 1424.44 & 1516.71 & 376.97 & 529.75 \\
\hline April & 1997 & 257.57 & 237.67 & 279.91 & 91.81 & 98.60 & 2011 & 1056.84 & 1394.81 & 1503.11 & 369.66 & 525.76 \\
\hline May & 1997 & 264.34 & 241.66 & 285.85 & 94.59 & 99.70 & 2011 & 1080.45 & 1425.96 & 1566.59 & 366.25 & 531.04 \\
\hline June & 1997 & 283.19 & 256.24 & 301.43 & 96.74 & 103.90 & 2011 & 1207.31 & 1593.40 & 1742.78 & 398.79 & 575.66 \\
\hline July & 1997 & 236.30 & 239.18 & 260.96 & 88.11 & 93.10 & 2011 & 1037.02 & 1368.65 & 1578.10 & 360.09 & 547.96 \\
\hline Aug & 1997 & 239.25 & 244.41 & 260.32 & 92.34 & 93.00 & 2011 & 1053.88 & 1390.90 & 1614.01 & 367.63 & 563.02 \\
\hline Sept & 1997 & 258.51 & 255.76 & 273.81 & 93.08 & 97.80 & 2011 & 1145.64 & 1512.01 & 1717.49 & 394.00 & 590.66 \\
\hline$O c t$ & 1997 & 268.89 & 260.30 & 276.70 & 99.60 & 97.80 & 2011 & 1106.17 & 1459.92 & 1662.87 & 378.38 & 568.80 \\
\hline Nov & 1997 & 286.90 & 272.25 & 302.56 & 103.60 & 105.60 & 2011 & 1145.67 & 1512.04 & 1714.88 & 406.81 & 608.93 \\
\hline Dec & 1997 & 316.00 & 293.44 & 332.27 & 109.49 & 115.30 & 2011 & 1247.80 & 1646.84 & 1819.32 & 446.49 & 650.99 \\
\hline
\end{tabular}


Appendix 2. Raw and Supporting Data

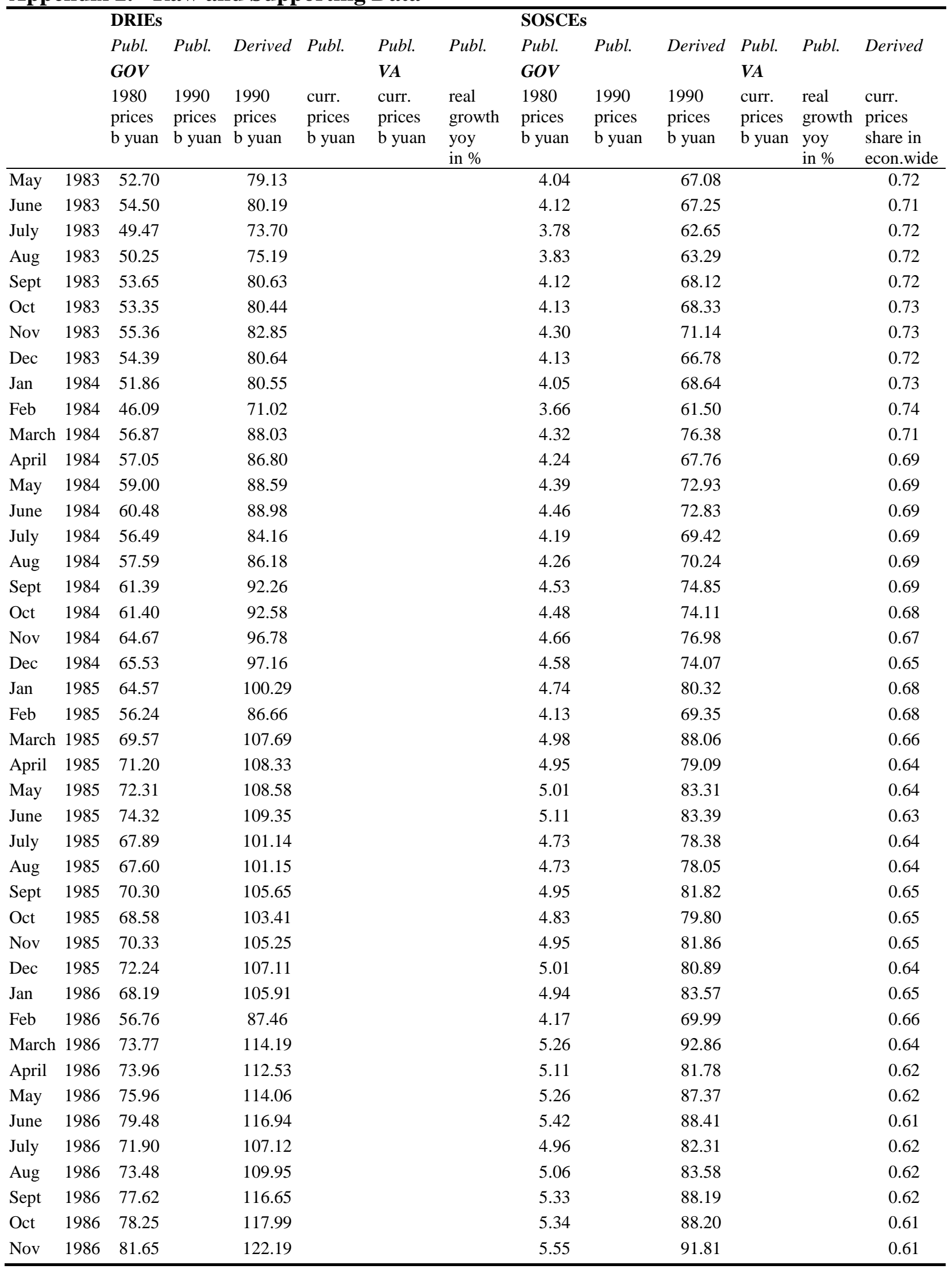




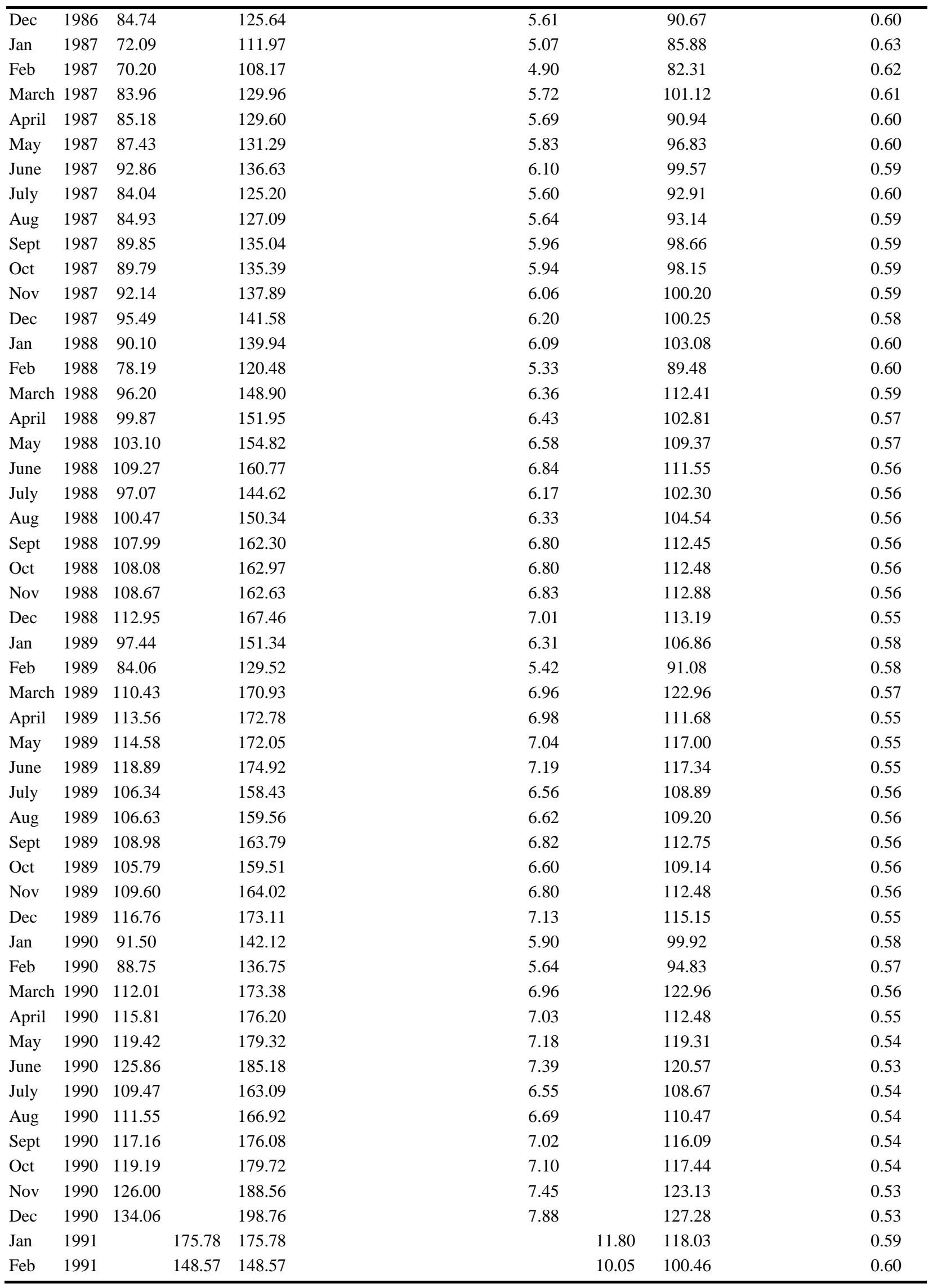




\begin{tabular}{|c|c|c|c|c|c|c|c|c|c|}
\hline March & 1991 & 189.39 & 189.39 & & & & 12.41 & 124.14 & 0.58 \\
\hline April & 1991 & 196.98 & 196.98 & & & & 12.61 & 126.10 & 0.56 \\
\hline May & 1991 & 203.37 & 203.37 & & & & 12.91 & 129.14 & 0.56 \\
\hline June & 1991 & 210.30 & 210.30 & & & & 13.13 & 131.29 & 0.55 \\
\hline July & 1991 & 185.63 & 185.63 & & & & 11.97 & 119.67 & 0.57 \\
\hline Aug & 1991 & 191.47 & 191.47 & & & & 12.21 & 122.06 & 0.56 \\
\hline Sept & 1991 & 202.22 & 202.22 & & & & 12.86 & 128.57 & 0.56 \\
\hline Oct & 1991 & 204.51 & 204.51 & & & & 12.85 & 128.50 & 0.55 \\
\hline Nov & 1991 & 206.92 & 206.92 & & & & 12.85 & 128.53 & 0.55 \\
\hline Dec & 1991 & 213.60 & 213.60 & & & & 12.96 & 129.59 & 0.53 \\
\hline Jan & 1992 & 198.42 & 198.42 & & & & 12.83 & 128.28 & 0.56 \\
\hline Feb & 1992 & 181.24 & 181.24 & & & & 11.72 & 117.16 & 0.56 \\
\hline March & 1992 & 227.47 & 227.47 & 215.53 & & & 14.26 & 142.57 & 0.54 \\
\hline April & 1992 & 232.89 & 232.89 & 232.89 & & & 14.30 & 142.99 & 0.53 \\
\hline May & 1992 & 237.31 & 237.31 & 237.89 & & & 14.31 & 143.13 & 0.52 \\
\hline June & 1992 & 251.58 & 251.58 & 251.63 & & & 14.67 & 146.74 & 0.51 \\
\hline July & 1992 & 228.80 & 228.80 & 232.57 & & & 13.59 & 135.92 & 0.51 \\
\hline Aug & 1992 & 232.10 & 232.10 & 237.25 & & & 13.63 & 136.26 & 0.51 \\
\hline Sept & 1992 & 244.11 & 244.11 & 251.08 & & & 14.18 & 141.79 & 0.50 \\
\hline Oct & 1992 & 250.26 & 250.26 & 261.54 & & & 14.43 & 144.33 & 0.50 \\
\hline Nov & 1992 & 260.88 & 260.88 & 270.84 & & & 14.83 & 148.32 & 0.49 \\
\hline Dec & 1992 & 282.38 & 282.38 & 302.32 & & & 15.35 & 153.53 & 0.47 \\
\hline Jan & 1993 & 217.91 & 217.91 & 232.05 & & & 13.12 & 131.18 & 0.54 \\
\hline Feb & 1993 & 240.87 & 240.87 & 265.50 & & & 13.96 & 139.61 & 0.52 \\
\hline March & 1993 & 286.94 & 286.94 & 320.01 & & & 16.29 & 162.86 & 0.51 \\
\hline April & 1993 & 291.67 & 291.67 & 329.40 & & & 16.22 & 162.16 & 0.50 \\
\hline May & 1993 & 302.21 & 302.21 & 346.04 & & & 16.42 & 164.22 & 0.49 \\
\hline June & 1993 & 327.45 & 327.45 & 376.69 & & & 17.03 & 170.27 & 0.47 \\
\hline July & 1993 & 286.29 & 286.29 & 338.45 & & & 15.23 & 152.33 & 0.48 \\
\hline Aug & 1993 & 286.42 & 286.42 & 340.12 & & & 15.38 & 153.85 & 0.48 \\
\hline Sept & 1993 & 290.80 & 290.80 & 342.26 & & & 15.62 & 156.23 & 0.48 \\
\hline Oct & 1993 & 291.18 & 291.18 & 342.62 & & & 15.44 & 154.43 & 0.47 \\
\hline Nov & 1993 & 310.13 & 310.13 & 362.18 & & & 16.17 & 161.73 & 0.47 \\
\hline Dec & 1993 & 366.44 & 366.44 & 431.25 & & & 18.07 & 180.70 & 0.44 \\
\hline Jan & 1994 & 290.33 & 290.33 & 343.49 & 124.0 & & 16.51 & 165.08 & 0.49 \\
\hline Feb & 1994 & 251.38 & 251.38 & 299.18 & 122.2 & & 13.95 & 139.50 & 0.48 \\
\hline March & 1994 & 340.90 & 340.90 & 406.80 & & & 18.15 & 181.45 & 0.45 \\
\hline April & 1994 & 349.95 & 349.95 & 427.29 & & & 18.31 & 183.11 & 0.45 \\
\hline May & 1994 & 364.26 & 364.26 & 451.89 & 144.7 & 17.3 & 18.56 & 185.58 & 0.43 \\
\hline June & 1994 & 387.14 & 387.14 & 481.43 & 135.2 & & 19.55 & 195.52 & 0.43 \\
\hline July & 1994 & 337.30 & 337.30 & 425.52 & 132.0 & 15.0 & 17.01 & 170.13 & 0.42 \\
\hline Aug & 1994 & 346.34 & 346.34 & 434.56 & & 7.6 & 17.37 & 173.72 & 0.42 \\
\hline Sept & 1994 & 366.27 & 366.27 & 458.01 & 140.0 & 11.8 & 18.28 & 182.76 & 0.42 \\
\hline Oct & 1994 & 375.34 & 375.34 & 472.58 & 142.6 & 24.3 & 18.68 & 186.81 & 0.42 \\
\hline Nov & 1994 & 397.32 & 397.32 & 499.00 & 149.8 & 23.6 & 19.59 & 195.90 & 0.41 \\
\hline Dec & 1994 & 446.90 & 446.90 & 577.29 & & & 21.41 & 214.12 & 0.40 \\
\hline Jan & 1995 & 299.67 & 299.67 & 421.92 & 123.7 & 11.4 & 16.34 & 163.44 & 0.42 \\
\hline Feb & 1995 & 274.03 & 274.03 & 416.76 & 122.2 & 15.5 & 14.89 & 148.88 & 0.42 \\
\hline March & 1995 & 358.09 & 358.09 & 531.35 & 155.0 & 16.4 & 19.00 & 190.04 & 0.41 \\
\hline April & 1995 & 374.63 & 374.63 & 550.87 & 156.8 & 15.4 & 19.20 & 192.04 & 0.39 \\
\hline May & 1995 & 381.79 & 381.79 & 566.46 & 158.6 & 13.1 & 19.30 & 193.01 & 0.39 \\
\hline
\end{tabular}




\begin{tabular}{|c|c|c|c|c|c|c|c|c|c|c|c|}
\hline June & 1995 & 404.06 & 404.06 & 594.17 & 164.7 & 13.9 & 20.05 & 200.48 & & & 0.38 \\
\hline July & 1995 & 348.39 & 348.39 & 529.18 & 146.2 & 13.6 & 17.83 & 178.32 & & & 0.39 \\
\hline Aug & 1995 & 351.06 & 351.06 & 529.61 & 145.6 & 11.8 & 18.00 & 180.00 & & & 0.39 \\
\hline Sept & 1995 & 370.31 & 370.31 & 554.13 & 147.5 & 11.4 & 19.07 & 190.70 & & & 0.39 \\
\hline Oct & 1995 & 381.07 & 381.07 & 569.79 & 151.3 & 12.9 & 19.32 & 193.17 & & & 0.38 \\
\hline Nov & 1995 & 409.10 & 409.10 & 603.20 & 164.0 & 12.1 & 20.42 & 204.21 & & & 0.38 \\
\hline Dec & 1995 & 465.08 & 465.08 & 686.55 & 186.9 & 14.9 & 22.59 & 225.92 & & & 0.37 \\
\hline Jan & 1996 & 347.66 & 347.66 & 477.37 & 146.2 & 16.9 & 18.36 & 183.61 & & & 0.38 \\
\hline Feb & 1996 & 297.03 & 297.03 & 410.25 & 125.6 & 10.8 & 15.71 & 157.15 & & & 0.38 \\
\hline March & 1996 & 394.26 & 394.26 & 534.88 & 158.8 & 13.6 & 20.01 & 200.09 & & & 0.37 \\
\hline April & 1996 & 406.76 & 406.76 & 553.63 & 162.7 & 13.7 & 20.34 & 203.36 & & & 0.36 \\
\hline May & 1996 & 414.69 & 414.69 & 565.94 & 164.3 & 13.1 & 20.59 & 205.91 & & & 0.36 \\
\hline June & 1996 & 441.73 & 441.73 & 599.32 & 152.2 & 13.8 & 21.41 & 214.10 & & & 0.35 \\
\hline July & 1996 & 380.68 & 380.68 & 525.81 & 152.4 & 12.2 & 18.98 & 189.76 & & & 0.36 \\
\hline Aug & 1996 & 374.63 & 374.63 & 517.35 & 150.3 & 10.6 & 18.83 & 188.31 & & & 0.36 \\
\hline Sept & 1996 & 401.11 & 401.11 & 547.63 & 158.5 & 13.7 & 20.41 & 204.13 & & & 0.37 \\
\hline Oct & 1996 & 412.96 & 412.96 & 563.52 & 164.1 & 13.3 & 21.04 & 210.40 & & & 0.37 \\
\hline Nov & 1996 & 437.29 & 437.29 & 592.51 & 173.7 & 13.4 & 22.10 & 221.02 & & & 0.36 \\
\hline Dec & 1996 & 499.15 & 499.15 & 667.48 & 196.5 & 13.0 & 24.50 & 245.04 & & & 0.35 \\
\hline Jan & 1997 & 378.75 & 378.75 & 513.96 & 150.0 & 10.3 & 19.61 & 196.10 & 90.8 & 6.8 & 0.38 \\
\hline Feb & 1997 & 318.18 & 318.18 & 438.90 & 125.1 & 10.4 & 16.41 & 164.06 & 77.9 & 4.4 & 0.39 \\
\hline March & 1997 & 440.45 & 440.45 & 587.07 & 172.2 & 13.5 & 21.75 & 217.50 & 99.3 & 8.7 & 0.36 \\
\hline April & 1997 & 452.02 & 452.02 & 598.32 & 174.3 & 11.9 & 21.72 & 217.19 & 98.6 & 6.8 & 0.35 \\
\hline May & 1997 & 463.90 & 463.90 & 610.77 & 178.0 & 11.9 & 21.87 & 218.68 & 99.7 & 6.2 & 0.35 \\
\hline June & 1997 & 496.99 & 496.99 & 649.30 & 187.7 & 12.0 & 23.12 & 231.23 & 103.9 & 8.0 & 0.34 \\
\hline July & 1997 & 414.69 & 414.69 & 558.83 & 162.5 & 8.4 & 20.08 & 200.77 & 93.1 & 5.8 & 0.36 \\
\hline Aug & 1997 & 419.87 & 419.87 & 559.43 & 162.1 & 10.9 & 20.41 & 204.13 & 93.0 & 8.4 & 0.36 \\
\hline Sept & 1997 & 453.68 & 453.68 & 600.30 & 170.5 & 11.1 & 21.99 & 219.85 & 97.8 & 7.7 & 0.36 \\
\hline Oct & 1997 & 471.89 & 471.89 & 615.68 & 172.3 & 11.8 & 22.49 & 224.92 & 97.8 & 6.9 & 0.35 \\
\hline Nov & 1997 & 503.49 & 503.49 & 651.15 & 188.4 & 11.6 & 23.80 & 238.04 & 105.6 & 7.7 & 0.35 \\
\hline Dec & 1997 & 554.57 & 554.57 & 716.75 & 206.9 & 9.2 & 25.90 & 259.01 & 115.3 & 5.7 & 0.35 \\
\hline Jan & 1998 & 365.37 & 365.37 & 475.10 & 137.8 & 1.8 & 18.29 & 182.92 & 83.6 & -2.9 & 0.36 \\
\hline Feb & 1998 & 364.96 & 364.96 & 468.32 & 135.4 & 9.5 & 18.32 & 183.17 & 81.0 & 11.7 & 0.35 \\
\hline March & 1998 & 460.85 & 460.85 & 583.44 & 167.8 & 9.0 & 22.18 & 221.78 & 96.3 & 3.9 & 0.34 \\
\hline April & 1998 & 482.79 & 482.79 & 581.70 & 166.6 & 7.2 & 22.35 & 223.45 & 94.1 & 2.8 & 0.33 \\
\hline May & 1998 & 492.75 & 492.75 & 592.34 & 168.1 & 8.0 & 22.58 & 225.84 & 94.1 & 4.0 & 0.33 \\
\hline June & 1998 & 519.55 & 519.55 & 618.09 & 176.0 & 7.9 & 23.11 & 231.13 & 96.7 & 2.7 & 0.32 \\
\hline July & 1998 & 451.35 & 451.35 & 545.85 & 155.3 & 7.6 & 20.59 & 205.93 & 87.4 & 5.1 & 0.33 \\
\hline Aug & 1998 & 461.36 & 461.36 & 556.72 & 158.2 & 7.9 & 20.76 & 207.62 & 88.4 & 3.1 & 0.33 \\
\hline Sept & 1998 & 513.15 & 513.15 & 608.94 & 172.9 & 10.2 & 22.98 & 229.83 & 95.9 & 5.8 & 0.33 \\
\hline Oct & 1998 & 526.68 & 526.68 & 626.97 & 178.5 & 10.6 & 23.46 & 234.57 & 99.7 & 6.0 & 0.33 \\
\hline Nov & 1998 & 553.32 & 553.32 & 650.65 & 185.0 & 11.0 & 24.91 & 249.05 & 104.4 & 7.2 & 0.33 \\
\hline Dec & 1998 & 596.06 & 596.06 & 707.23 & 201.9 & 11.5 & 26.85 & 268.46 & 114.2 & 8.0 & 0.33 \\
\hline Jan & 1999 & 444.44 & 444.44 & & 150.9 & 17.9 & & & 84.7 & 16.9 & 0.32 \\
\hline Feb & 1999 & 381.35 & 381.35 & & 128.2 & 2.1 & & & 74.1 & 0.5 & 0.33 \\
\hline March & 1999 & 513.64 & 513.64 & & 167.0 & 9.0 & & & 94.7 & 6.8 & 0.33 \\
\hline April & 1999 & 525.86 & 525.86 & & 170.0 & 9.1 & & & 97.9 & 7.1 & 0.33 \\
\hline May & 1999 & 532.36 & 532.36 & & 171.6 & 8.9 & & & 97.7 & 5.6 & 0.33 \\
\hline June & 1999 & 564.50 & 564.50 & & 181.7 & 9.1 & & & 102.8 & 7.5 & 0.33 \\
\hline July & 1999 & 499.51 & 499.51 & & 162.1 & 9.3 & & & 93.0 & 7.8 & 0.33 \\
\hline Aug & 1999 & 513.87 & 513.87 & & 166.6 & 9.5 & & & 95.6 & 8.4 & 0.33 \\
\hline
\end{tabular}




\begin{tabular}{|c|c|c|c|c|c|c|c|c|c|}
\hline Sept & 1999 & 547.37 & 547.37 & & 176.1 & 8.2 & 101.8 & 7.9 & 0.33 \\
\hline Oct & 1999 & 562.56 & 562.56 & & 181.8 & 7.0 & 104.5 & 6.8 & 0.33 \\
\hline Nov & 1999 & 597.03 & 597.03 & & 191.9 & 7.6 & 110.7 & 6.5 & 0.33 \\
\hline Dec & 1999 & 663.67 & 663.67 & & 213.0 & 7.4 & 119.0 & 6.5 & 0.32 \\
\hline Jan & 2000 & 502.89 & 502.89 & & 164.3 & 8.9 & 96.3 & 5.2 & 0.35 \\
\hline $\mathrm{Feb}$ & 2000 & 445.75 & 445.75 & & 148.7 & 12.0 & 90.5 & 10.3 & 0.36 \\
\hline March & 2000 & 580.60 & 580.60 & & 188.2 & 11.9 & 114.1 & 10.6 & 0.36 \\
\hline April & 2000 & 597.40 & 597.40 & & 192.9 & 11.4 & 115.3 & 10.8 & 0.35 \\
\hline May & 2000 & 610.35 & 610.35 & & 196.3 & 11.5 & 115.8 & 10.6 & 0.35 \\
\hline June & 2000 & 651.03 & 651.03 & & 209.2 & 12.2 & 121.8 & 11.9 & 0.34 \\
\hline July & 2000 & & & & 196.0 & 12.8 & 117.1 & 12.8 & 0.35 \\
\hline Aug & 2000 & & & & 201.2 & 12.8 & 120.7 & 12.1 & 0.35 \\
\hline Sept & 2000 & & & & 209.3 & 12.0 & 125.2 & 11.2 & 0.35 \\
\hline Oct & 2000 & & & & 209.5 & 11.4 & 123.3 & 8.3 & 0.35 \\
\hline Nov & 2000 & & & & 217.1 & 10.6 & 128.0 & 9.1 & 0.35 \\
\hline Dec & 2000 & & & & 235.8 & 10.4 & 135.1 & 8.5 & 0.34 \\
\hline Jan & 2001 & & & & 169.5 & 2.3 & 104.5 & 2.3 & 0.38 \\
\hline $\mathrm{Feb}$ & 2001 & & & & 193.4 & 19.0 & 115.1 & 19.3 & 0.37 \\
\hline March & 2001 & & & & 223.9 & 12.1 & 128.8 & 9.5 & 0.36 \\
\hline April & 2001 & & & & 226.6 & 11.5 & 129.9 & 10.7 & 0.35 \\
\hline May & 2001 & & & & 227.9 & 10.2 & 128.9 & 8.8 & 0.35 \\
\hline June & 2001 & & & & 239.8 & 10.1 & 133.4 & 9.0 & 0.34 \\
\hline July & 2001 & & & & 220.1 & 8.1 & 124.5 & 7.9 & 0.35 \\
\hline Aug & 2001 & & & & 223.3 & 8.1 & 125.7 & 7.9 & 0.35 \\
\hline Sept & 2001 & & & & 235.2 & 9.5 & 131.4 & 9.2 & 0.35 \\
\hline Oct & 2001 & & & & 233.2 & 8.8 & 129.2 & 6.5 & 0.34 \\
\hline Nov & 2001 & & & & 238.9 & 7.9 & 130.4 & 4.3 & 0.34 \\
\hline Dec & 2001 & & & & 263.2 & 8.7 & 138.0 & 5.0 & 0.32 \\
\hline Jan & 2002 & & & & 215.8 & 18.6 & 123.2 & 18.5 & 0.38 \\
\hline Feb & 2002 & & & & 188.0 & 2.7 & 103.5 & 0.2 & 0.37 \\
\hline March & 2002 & & & & 245.6 & 10.9 & 131.1 & 8.4 & 0.35 \\
\hline April & 2002 & & & & 256.9 & 12.1 & 137.5 & 10.9 & 0.36 \\
\hline May & 2002 & & & & 261.7 & 12.9 & 139.0 & 11.2 & 0.35 \\
\hline June & 2002 & & & & 278.0 & 12.4 & 143.3 & 10.0 & 0.34 \\
\hline July & 2002 & & & & 256.8 & 12.8 & 135.6 & 11.6 & 0.35 \\
\hline Aug & 2002 & & & & 263.4 & 12.7 & 138.8 & 11.2 & 0.35 \\
\hline Sept & 2002 & & & & 282.5 & 13.8 & 147.1 & 14.0 & 0.35 \\
\hline Oct & 2002 & & & & 283.0 & 14.2 & 148.0 & 13.8 & 0.35 \\
\hline Nov & 2002 & & & & 294.9 & 14.5 & 153.7 & 14.2 & 0.35 \\
\hline Dec & 2002 & & & & 321.6 & 14.9 & 163.7 & 14.1 & 0.34 \\
\hline Jan & 2003 & & & 927.0 & 266.2 & 14.8 & 146.5 & 14.5 & 0.41 \\
\hline $\mathrm{Feb}$ & 2003 & & & 888.0 & 254.7 & 19.8 & 136.6 & 20.1 & 0.40 \\
\hline March & 2003 & & & 1096.2 & 313.4 & 16.9 & 162.0 & 15.1 & 0.39 \\
\hline April & 2003 & & & 1120.4 & 319.7 & 14.9 & 162.2 & 11.9 & 0.38 \\
\hline May & 2003 & & & 1119.2 & 319.0 & 13.7 & 157.3 & 10.5 & 0.37 \\
\hline June & 2003 & & & 1227.7 & 363.3 & 16.9 & 161.3 & 13.7 & 0.33 \\
\hline July & 2003 & & & 1150.8 & 341.0 & 16.5 & 157.3 & 14.0 & 0.34 \\
\hline Aug & 2003 & & & 1181.1 & 349.8 & 17.1 & 160.0 & 14.0 & 0.34 \\
\hline Sept & 2003 & & & 1250.5 & 370.4 & 16.3 & 167.2 & 11.6 & 0.34 \\
\hline Oct & 2003 & & & 1268.0 & 375.3 & 17.2 & 165.8 & 12.6 & 0.33 \\
\hline Nov & 2003 & & & 1339.9 & 396.6 & 17.9 & 175.1 & 15.5 & 0.33 \\
\hline
\end{tabular}




\begin{tabular}{|c|c|c|c|c|c|c|c|}
\hline Dec & 2003 & 1467.8 & 435.1 & 18.1 & 189.5 & 15.3 & 0.33 \\
\hline Jan & 2004 & 1125.6 & 334.42 & 7.2 & 158.8 & 7.5 & 0.39 \\
\hline Feb & 2004 & 1275.9 & 370.93 & 23.2 & 166.1 & 20.0 & 0.37 \\
\hline March & 2004 & 1482.4 & 426.48 & 19.4 & 183.0 & 15.2 & 0.35 \\
\hline April & 2004 & 1513.9 & 437.05 & 19.1 & 186.8 & 15.8 & 0.35 \\
\hline May & 2004 & 1496.2 & 430.96 & 17.5 & 180.6 & 13.8 & 0.35 \\
\hline June & 2004 & 1598.8 & 460.79 & 16.2 & 187.8 & 14.0 & 0.34 \\
\hline July & 2004 & 1500.9 & 440.90 & 15.5 & 187.1 & 12.7 & 0.35 \\
\hline Aug & 2004 & 1554.9 & 454.45 & 15.9 & 191.6 & 12.8 & 0.35 \\
\hline Sept & 2004 & 1657.6 & 481.24 & 16.1 & 196.6 & 13.3 & 0.34 \\
\hline Oct & 2004 & 1676.3 & 488.52 & 15.7 & 204.2 & 14.0 & 0.35 \\
\hline Nov & 2004 & 1742.2 & 508.39 & 14.8 & 210.5 & 12.5 & 0.34 \\
\hline Dec & 2004 & 1896.7 & 548.80 & 14.4 & 221.8 & 12.4 & 0.33 \\
\hline Jan & 2005 & 1679.4 & 484.37 & 20.9 & 217.3 & 17.0 & 0.40 \\
\hline $\mathrm{Feb}$ & 2005 & 1523.2 & 425.54 & 7.6 & 184.3 & 4.0 & 0.39 \\
\hline March & 2005 & 1901.3 & 536.70 & 15.1 & 220.3 & 11.8 & 0.37 \\
\hline April & 2005 & 1978.9 & 564.65 & 16.0 & 230.5 & 11.9 & 0.37 \\
\hline May & 2005 & 2003.6 & 570.16 & 16.6 & 226.3 & 11.3 & 0.36 \\
\hline June & 2005 & 2184.9 & 619.14 & 16.8 & 234.4 & 10.2 & 0.34 \\
\hline July & 2005 & 2036.8 & 581.10 & 16.1 & 231.5 & 11.3 & 0.36 \\
\hline Aug & 2005 & 2092.0 & 596.75 & 16.0 & 237.8 & 11.1 & 0.36 \\
\hline Sept & 2005 & 2206.3 & 627.53 & 16.5 & 244.8 & 11.3 & 0.35 \\
\hline Oct & 2005 & 2221.3 & 631.99 & 16.1 & 241.6 & 8.9 & 0.34 \\
\hline Nov & 2005 & 2326.6 & 659.02 & 16.6 & 248.2 & 9.6 & 0.34 \\
\hline Dec & 2005 & 2544.6 & 671.24 & 16.5 & 243.1 & 10.3 & 0.33 \\
\hline Jan & 2006 & 1641.9 & 563.96 & 12.8 & 232.7 & 6.9 & 0.40 \\
\hline Feb & 2006 & 1978.7 & 547.31 & 20.1 & 217.0 & 12.4 & 0.37 \\
\hline March & 2006 & 2417.7 & 667.97 & 17.8 & 247.6 & 9.0 & 0.35 \\
\hline April & 2006 & 2488.1 & 681.98 & 16.6 & 246.3 & 10.8 & 0.36 \\
\hline May & 2006 & 2570.6 & 705.99 & 17.9 & 251.5 & 13.6 & 0.35 \\
\hline June & 2006 & 2853.0 & 781.78 & 19.5 & 266.5 & 15.4 & 0.34 \\
\hline July & 2006 & 2616.2 & 719.98 & 16.7 & 258.5 & 12.7 & 0.36 \\
\hline Aug & 2006 & 2670.5 & 735.55 & 15.7 & 265.3 & 12.1 & 0.36 \\
\hline Sept & 2006 & 2830.0 & 775.41 & 16.1 & 272.3 & 12.4 & 0.35 \\
\hline Oct & 2006 & 2791.7 & 760.14 & 14.7 & 262.7 & 12.5 & 0.35 \\
\hline Nov & 2006 & 2928.6 & 793.60 & 14.9 & 270.1 & 13.6 & 0.36 \\
\hline Dec & 2006 & 3159.7 & & 14.7 & & 15.8 & 0.36 \\
\hline Jan & 2007 & 2748.3 & & 24.2 & & 20.7 & 0.40 \\
\hline Feb & 2007 & 2381.1 & & 12.6 & & 10.1 & 0.37 \\
\hline March & 2007 & 3060.6 & & 17.6 & & 13.6 & 0.35 \\
\hline April & 2007 & 3158.5 & & 17.4 & & 13.2 & 0.35 \\
\hline May & 2007 & 3281.0 & & 18.1 & & 13.0 & 0.35 \\
\hline June & 2007 & 3690.9 & & 19.4 & & 13.3 & 0.33 \\
\hline July & 2007 & 3333.0 & & 18.0 & & 12.5 & 0.35 \\
\hline Aug & 2007 & 3389.8 & & 17.5 & & 13.6 & 0.35 \\
\hline Sept & 2007 & 3635.2 & & 18.9 & & 15.6 & 0.35 \\
\hline Oct & 2007 & 3586.9 & & 17.9 & & 13.6 & 0.35 \\
\hline Nov & 2007 & 3754.4 & & 17.3 & & 14.2 & 0.36 \\
\hline Dec & 2007 & 4053.2 & & 17.4 & & 13.6 & 0.36 \\
\hline Jan & 2008 & 3446.8 & & 15.4 & & 11.9 & 0.40 \\
\hline Feb & 2008 & 3036.5 & & 15.4 & & 11.5 & 0.37 \\
\hline
\end{tabular}




\begin{tabular}{|c|c|c|c|c|c|}
\hline March & 2008 & 3998.9 & 17.8 & 14.3 & 0.34 \\
\hline April & 2008 & 4070.9 & 15.7 & 11.3 & 0.35 \\
\hline May & 2008 & 4240.3 & 16.0 & 12.6 & 0.34 \\
\hline June & 2008 & 4765.5 & 16.0 & 12.4 & 0.33 \\
\hline July & 2008 & 4349.4 & 14.7 & 11.8 & 0.35 \\
\hline Aug & 2008 & 4335.7 & 12.8 & 9.7 & 0.35 \\
\hline Sept & 2008 & 4493.1 & 11.4 & 7.4 & 0.34 \\
\hline Oct & 2008 & 4167.7 & 8.2 & 4.5 & 0.34 \\
\hline Nov & 2008 & 4028.3 & 5.4 & 0.7 & 0.35 \\
\hline Dec & 2008 & 4244.3 & 5.7 & -0.6 & 0.34 \\
\hline Jan & 2009 & 3136.5 & -3.4 & -5.6 & 0.40 \\
\hline $\mathrm{Feb}$ & 2009 & 3285.3 & 11.0 & 3.6 & 0.35 \\
\hline March & 2009 & 4156.2 & 8.3 & 2.7 & 0.33 \\
\hline April & 2009 & 4173.5 & 7.3 & 2.3 & 0.34 \\
\hline May & 2009 & 4420.9 & 8.9 & 2.4 & 0.33 \\
\hline June & 2009 & 5021.7 & 10.7 & 5.7 & 0.33 \\
\hline July & 2009 & 4619.2 & 10.8 & 7.4 & 0.35 \\
\hline Aug & 2009 & 4737.3 & 12.3 & 8.6 & 0.35 \\
\hline Sept & 2009 & 5067.0 & 13.9 & 11.8 & 0.34 \\
\hline Oct & 2009 & 4960.2 & 16.1 & 13.7 & 0.34 \\
\hline Nov & 2009 & 5191.8 & 19.2 & 19.0 & 0.36 \\
\hline Dec & 2009 & 5576.0 & 18.5 & 21.7 & 0.36 \\
\hline Jan & 2010 & 4744.2 & 28.6 & 28.1 & 0.41 \\
\hline Feb & 2010 & 4135.7 & 12.8 & 13.3 & 0.37 \\
\hline March & 2010 & 5525.5 & 18.1 & 18.2 & 0.34 \\
\hline April & 2010 & 5619.1 & 17.8 & 17.6 & 0.35 \\
\hline May & 2010 & 5865.3 & 16.5 & 16.8 & 0.34 \\
\hline June & 2010 & 6341.1 & 13.7 & 13.3 & 0.33 \\
\hline July & 2010 & 5768.3 & 13.4 & 11.4 & 0.35 \\
\hline Aug & 2010 & 5947.7 & 13.9 & 11.7 & 0.35 \\
\hline Sept & 2010 & 6372.8 & 13.3 & 11.0 & 0.35 \\
\hline Oct & 2010 & 6288.0 & 13.1 & 10.6 & 0.35 \\
\hline Nov & 2010 & 6656.4 & 13.3 & 10.9 & 0.36 \\
\hline Dec & 2010 & 7155.2 & 13.5 & 9.8 & 0.36 \\
\hline Jan & 2011 & 5738.8 & 13.3 & 10.7 & 0.41 \\
\hline $\mathrm{Feb}$ & 2011 & 5151.7 & 14.9 & 10.5 & 0.36 \\
\hline March & 2011 & 6850.5 & 14.8 & 12.9 & 0.35 \\
\hline April & 2011 & 6789.1 & 13.4 & 10.4 & 0.35 \\
\hline May & 2011 & 7075.8 & 13.3 & 8.9 & 0.34 \\
\hline June & 2011 & 7871.6 & 15.1 & 10.7 & 0.33 \\
\hline July & 2011 & 7127.8 & 14.1 & 9.5 & 0.35 \\
\hline Aug & 2011 & 7290.0 & 13.5 & 9.4 & 0.35 \\
\hline Sept & 2011 & 7757.4 & 13.8 & 9.9 & 0.34 \\
\hline Oct & 2011 & 7510.7 & 13.2 & 8.9 & 0.34 \\
\hline Nov & 2011 & 7745.6 & 12.4 & 7.8 & 0.36 \\
\hline Dec & 2011 & 8217.3 & 12.8 & 9.2 & 0.36 \\
\hline
\end{tabular}

Publ.: published data (as is), with approximated January real VA growth rates for DRIEs and SOSCEs starting 2006. Derived data: manipulations are described in the text of the article. Thus, the derived data on DRIE and SOSCE GOV in 1990 prices involve bridging the published series in 1980 and 1990 prices, assumptions about the aggregate share of the first four months of 1983 in the annual total, and, in the case of the SOSCEs, the derivation of 1993-1996 values. 
Appendix 3. Annual Data

\begin{tabular}{|c|c|c|c|c|}
\hline & \multicolumn{2}{|c|}{ Value-added } & \multirow{2}{*}{$\begin{array}{l}\boldsymbol{G O} \boldsymbol{V} \\
\text { Economy- } \\
\text { wide }\end{array}$} & \multirow[b]{2}{*}{ SOSCEs } \\
\hline & Nominal & $\begin{array}{l}\text { Real } \\
\text { growth } \\
1978=100\end{array}$ & & \\
\hline 1983 & 2375.6 & 144.5 & 6461 & 4739.4 \\
\hline 1984 & 2789.0 & 166.0 & 7617 & 5262.7 \\
\hline 1985 & 3448.7 & 196.2 & 9716 & 6302.1 \\
\hline 1986 & 3967.0 & 215.2 & 11194 & 6971.1 \\
\hline 1987 & 4585.8 & 243.6 & 13813 & 8250.1 \\
\hline 1988 & 5777.2 & 280.8 & 18224 & 10351.3 \\
\hline 1989 & 6484.0 & 295.0 & 22017 & 12342.9 \\
\hline 1990 & 6858.0 & 304.9 & 23924 & 13063.8 \\
\hline 1991 & 8087.1 & 348.8 & 26625 & 14954.6 \\
\hline 1992 & 10284.5 & 422.6 & 34599 & 17824.2 \\
\hline 1993 & 14188.0 & 507.5 & 48402 & 22724.7 \\
\hline 1994 & 19480.7 & 603.5 & 70176 & 26200.8 \\
\hline 1995 & 24950.6 & 688.2 & 91894 & 31220.0 \\
\hline 1996 & 29447.6 & 774.3 & 99595 & 36173.0 \\
\hline 1997 & 32921.4 & 861.9 & 113733 & 35968.0 \\
\hline 1998 & 34018.4 & 938.6 & 119048 & 33621.0 \\
\hline 1999 & 35861.5 & 1018.6 & 126110 & 35571.0 \\
\hline 2000 & 40033.6 & 1118.3 & & \\
\hline 2001 & 43580.6 & 1215.2 & & \\
\hline 2002 & 47431.3 & 1336.4 & & \\
\hline 2003 & 54945.5 & 1506.8 & & \\
\hline 2004 & 65210.0 & 1680.2 & & \\
\hline 2005 & 77230.8 & 1874.7 & & \\
\hline 2006 & 91310.9 & 2116.1 & & \\
\hline 2007 & 110534.9 & 2431.5 & & \\
\hline 2008 & 130260.2 & 2673.0 & & \\
\hline 2009 & 135239.9 & 2906.4 & & \\
\hline 2010 & 160722.2 & 3257.0 & & \\
\hline 2011 & 188470.2 & 3595.0 & & \\
\hline
\end{tabular}

Sources: Value-added: China Statistical Yearbook 2012, p. 44; GOV: Industrial Yearbook 2011, p. 21. 